\title{
Can we detect regional methane anomalies? A comparison between three observing systems
}

\author{
Cindy Cressot $^{1}$, Isabelle Pison ${ }^{1}$, Peter J. Rayner ${ }^{2}$, Philippe Bousquet ${ }^{1}$, Audrey Fortems-Cheiney ${ }^{1}$, and \\ Frédéric Chevallier ${ }^{1}$ \\ ${ }^{1}$ Laboratoire des Sciences du Climat et de l'Environnement, CEA/CNRS/UVSQ, Gif-sur-Yvette, France \\ ${ }^{2}$ School of Earth Sciences, University of Melbourne, Melbourne, Australia \\ Correspondence to: Isabelle Pison (isabelle.pison@1sce.ipsl.fr)
}

Received: 17 March 2016 - Published in Atmos. Chem. Phys. Discuss.: 18 March 2016

Revised: 17 June 201 - Accepted: 5 July 2016 - Published: 25 July 2016

\begin{abstract}
A Bayesian inversion system is used to evaluate the capability of the current global surface network and of the space-borne GOSAT/TANSO-FTS and IASI instruments to quantify surface flux anomalies of methane at various spatial (global, semi-hemispheric and regional) and time (seasonal, yearly, 3-yearly) scales. The evaluation is based on a signalto-noise ratio analysis, the signal being the methane fluxes inferred from the surface-based inversion from 2000 to 2011 and the noise (i.e., precision) of each of the three observing systems being computed from the Bayesian equation. At the global and semi-hemispheric scales, all observing systems detect flux anomalies at most of the tested timescales. At the regional scale, some seasonal flux anomalies are detected by the three observing systems, but year-to-year anomalies and longer-term trends are only poorly detected. Moreover, reliably detected regions depend on the reference surface-based inversion used as the signal. Indeed, tropical flux inter-annual variability, for instance, can be attributed mostly to Africa in the reference inversion or spread between tropical regions in Africa and America. Our results show that inter-annual analyses of methane emissions inferred by atmospheric inversions should always include an uncertainty assessment and that the attribution of current trends in atmospheric methane to particular regions' needs increased effort, for instance, gathering more observations (in the future) and improving transport models. At all scales, GOSAT generally shows the best performance of the three observing systems.
\end{abstract}

\section{Introduction}

As the second most important anthropogenic greenhouse gas after carbon dioxide in terms of radiative forcing, methane $\left(\mathrm{CH}_{4}\right)$ is an important climate driver. Monitoring atmospheric $\mathrm{CH}_{4}$ concentrations and their driving emissions are therefore primary research objectives for Earth observation science. These two objectives are combined in atmospheric inversion systems. Such systems infer the space-time variations of the global or regional emissions from the assimilation of observations of atmospheric mole fractions into chemistry-transport models (CTMs) (Houweling et al., 1999; Bergamaschi et al., 2007; Bousquet et al., 2011; Pison et al., 2013). For these systems, explaining the trends of $\mathrm{CH}_{4}$ concentrations, such as their stability between 2000 and 2006 and their later increase (Kirschke et al., 2013), is a major scientific objective. Despite considerable efforts in developing observing systems at the Earth's surface, in the atmosphere and from space, the inferred fluxes are associated with large uncertainties. This still allows diverging interpretations of the trends, depending on which CTM is used or on how the inversion setup is defined (Bousquet et al., 2006, 2011; Rigby et al., 2008; Dlugokencky et al., 2009; Bergamaschi et al., 2013). In principle, the Bayesian framework should reconcile all well-tuned inversion systems because it characterizes the uncertainty of each inversion product at all space-time scales, thereby weighting each scenario suggested by the inversion approach. In practice, posterior uncertainties are often difficult to compute and are also affected by observation uncertainties or mis-specified prior uncertainties (Berchet et al., 2015). In a previous study, Cressot et al. (2014) applied objective tuning methods imported from nu- 
merical weather prediction (Desroziers et al., 2005) within a robust Monte Carlo approach to optimize the input error covariance matrices of a global $\mathrm{CH}_{4}$ inversion system. Here, we use their results as a starting point to characterize the uncertainty of the year-to-year variations of the inferred fluxes at various temporal (e.g., seasonal, annual, 3yearly, monthly) and spatial (global, latitudinal bands, large regions) scales in order to document which anomaly signals from the inversions are reliable and which are not reliable within our framework. To do so, three different global $\mathrm{CH}_{4}$ observation systems are considered: surface sites from various global networks (flasks and continuous), the spaceborne Infrared Atmospheric Sounding Interferometer (IASI) that provides a middle-to-upper tropospheric column and the Thermal And Near-infrared Sensor for carbon Observation Fourier transform spectrometer (TANSO-FTS), that observes the total column from space. Using the flux anomalies of the surface inversion as the signal, signal-to-noise ratios for different temporal and spatial scales are computed, the noise being the uncertainty (precision) of the year-to-year changes of the inferred fluxes for each observing system. Signal-to-noise ratios are then considered as a statistical criterion to evaluate the ability of an observing system to retrieve the $\mathrm{CH}_{4}$ flux inter-annual variability.

The paper is structured as follows. The theoretical framework and the different data sets are presented in Sect. 2. The signal-to-noise ratios are presented in Sect. 3 and further discussed in Sect. 4.

\section{Method}

\subsection{Inversion framework}

Our inversion system is based on a variational formulation of Bayes' theorem, as detailed by Chevallier et al. (2005), which has been adapted to the inversion of $\mathrm{CH}_{4}$ fluxes by Pison et al. (2009). It allows inferring grid-point-scale fluxes, thereby avoiding gross aggregation errors (Kaminski et al., 2001), while assimilating the large flow of satellite data at appropriate observation times and locations. It ingests observations of $\mathrm{CH}_{4}$ mole fractions and prior information about the variables that are to be optimized, with associated error covariance matrices. Bayesian error statistics of the inferred variables are computed from a Monte Carlo ensemble of inversions which is consistent with the assigned-prior and observation errors (Chevallier et al., 2007). The inversion system includes the LMDZ transport model of Hourdin et al. (2006) at a resolution of $3.75^{\circ} \times 2.5^{\circ}$ (longitude by latitude) for 19 vertical levels nudged to ECMWF-analyzed winds in its on-line mode. Here, we use its off-line mode that exploits the output variables of the on-line version. We couple it to a simplified chemistry module to represent the interactions between $\mathrm{CH}_{4}$ and the hydroxyl radical $(\mathrm{OH})$, its main sink in the atmosphere, and between methyl chloroform (MCF) and $\mathrm{OH}$. Note that the loss due to chlorine in the marine boundary layer is not implemented yet in this model. When it assimilates both $\mathrm{CH}_{4}$ and $\mathrm{MCF}$ mole fractions, as is done here, it synergistically optimizes both $\mathrm{CH}_{4}$ surface sources at weekly and model grid resolution and $\mathrm{OH}$ at weekly resolution over four latitude bands $(-90 /-30,-30 / 0,0 / 30,30 / 90)$. This setup therefore dynamically distinguishes between $\mathrm{CH}_{4}$ net surface emissions (soil uptake included) and atmospheric loss. The system iteratively minimizes the Bayesian cost function (made nonquadratic by the nonlinear chemistry) using the M1QN3 algorithm (Gilbert and Lemaréchal, 1989).

This system is applied here to assimilate data from each of three $\mathrm{CH}_{4}$ observing systems together with data from a $\mathrm{MCF}$ observing system (to constrain $\mathrm{OH}$ concentrations), in the configuration used by Cressot et al. (2014). The reader is referred to Cressot et al. (2014) for a detailed description of this configuration. It is important here to recall that the prior fluxes (fires excepted) have no inter-annual variability (IAV). This choice is made for IAV to be generated by atmospheric observations and atmospheric transport and chemistry and not by prior IAVs of emissions (and sinks) which are still uncertain or even controversial (e.g., Schaefer et al., 2016; Hausmann et al., 2016; Nisbet et al., 2014).

Two types of inversions are presented in this study:

- a reference inversion (hereafter called REFSURF) using $\mathrm{CH}_{4}$ and MCF surface measurements from December 1999 to December 2011; and

- three ensembles of inversions (see Sect. 2.3 for the use of these), one using surface measurements only (called SURF hereafter), one using IASI data and MCF observations only (called IASI hereafter) and one using TANSO-FTS data and MCF observations only (called GOSAT hereafter, from the name of the platform, Greenhouse Gases Observing Satellite); each ensemble consists of 101 -year inversions from October 2009 to September 2010, with respective inversion setups tuned according to an objective analysis described in Cressot et al. (2014).

For all inversions, the minimization of the nonquadratic cost function is stopped when the ratio of the final to the initial norm of the gradient is less than 0.01 .

\subsection{Data sets}

In order to have continuous and homogeneous surface data throughout the extended assimilation window of REFSURF, we restrict the methane site list to 36 instead of 49 , as used in Cressot et al. (2014). They come from the National Oceanic and Atmospheric Administration (NOAA) global cooperative air sampling network (Dlugokencky et al., 1994, 2009), the Commonwealth Scientific and Industrial Research Organisation (CSIRO) (Francey et al., 1999) and the National Institute of Water and Atmospheric Research (NIWA) (Lowe 


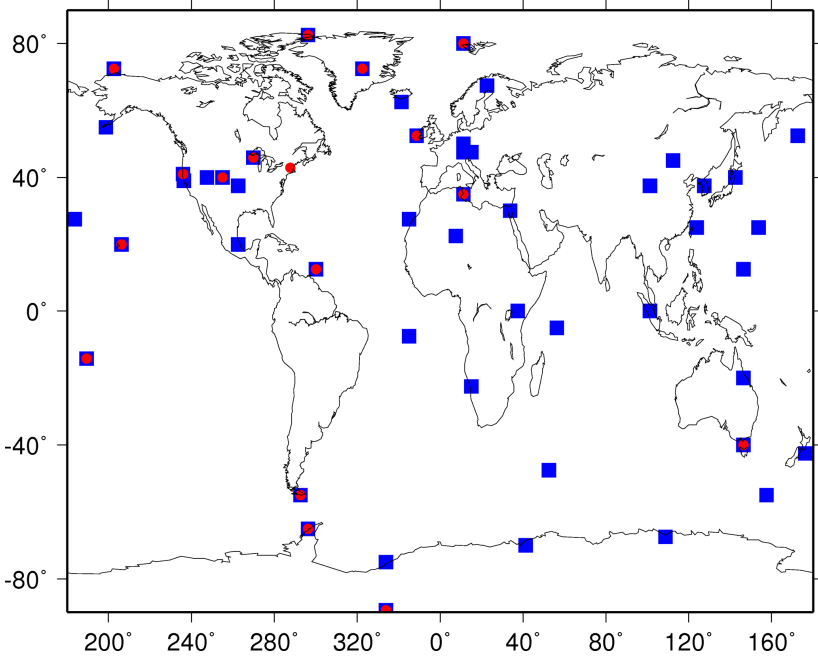

Figure 1. Surface sites from the NOAA, CSIRO, NIWA and EC networks used in this study with red circles for surface sites observing MCF dry air mole fractions and blue squares for surface sites observing $\mathrm{CH}_{4}$ dry air mole fractions.

et al., 1991). We also use station Alert (ALT) from Environment Canada (EC) (Worthy et al., 2009). MCF measurements are provided by 11 NOAA surface sites (Montzka et al., 2011) and are used to constrain $\mathrm{OH}$ concentrations (Pison et al., 2009). The surface sites used in our inversions are presented in Fig. 1.

We use observations of the middle-to-upper tropospheric $\mathrm{CH}_{4}$ column made by IASI, a thermal interferometer onboard the Meteorological Operational (MetOp) satellites. This quantity is retrieved based on a nonlinear inference scheme (Crevoisier et al., 2009) within $30^{\circ}$ of the Equator over both land and ocean at about 09:30/21:30 LT, with an accuracy of $1.2 \%(\approx 20 \mathrm{ppb})$.

Last, we use observations of the $\mathrm{CH}_{4}$ atmospheric total column over land from TANSO-FTS, a near-infrared spectrometer onboard GOSAT. Total columns are retrieved by optimal estimation using the algorithm of Parker et al. (2011) and with a precision of $\sim 0.6 \%(\approx 10 \mathrm{ppb})$.

The averaging kernel or weighting function and the prior profile (when available) of each IASI or TANSO-FTS retrieval are directly accounted for in the inversion system following Connor et al. (2008).

\subsection{Error statistics}

The error statistics are described in detail in Cressot et al. (2014). For the fluxes, the spatial correlations are defined by $e$-folding lengths of $500 \mathrm{~km}$ over land and $1000 \mathrm{~km}$ over ocean (no correlation between land and ocean); time correlations are defined by an $e$-folding length of 2 weeks. It was checked that these choices led to a budget uncertainty which is consistent with the uncertainty of bottom-up inventories as described in Kirschke et al. (2013).
The input error statistics for the prior and the observations are tuned using objective diagnostics as described by Cressot et al. (2014). This means that they exhibit some objectivity that is seen to translate into realistic Bayesian posterior error statistics, which in particular make all present inversions statistically consistent at the annual and global or regional scales (Cressot et al., 2014).

In order to keep the computational burden to a reasonable level, we compute the posterior error statistics from a Monte Carlo inversion ensemble of 10 times 1 year for each of the three observing systems (ensembles GOSAT, IASI and SURF as described in Sect. 2.1).

The posterior error statistics (the "noise" for our study) are estimated as follows:

- We estimate the ratio of posterior-to-prior standard deviations of the annual flux errors $r=\frac{\sigma_{a}}{\sigma_{b}}$ from the ensemble, a quantity which is more robust than $\sigma_{a}$ and $\sigma_{b}$ individually for small ensembles (because some of the underspread affects the prior and the posterior in a similar way). The number of members in the ensemble depends on the timescale, e.g., 10 members for the yearly timescale (10 inversions, each one covering 1 year), 120 members for the monthly timescale.

- We estimate the posterior standard deviations of the annual flux errors by multiplying $r$ by the known value of $\sigma_{b}$, i.e., the one implied by our error covariance matrix (computed from the above assumptions).

- The posterior standard deviations of the multi-annual flux errors for $n$ years are obtained by applying a factor of $\frac{1}{\sqrt{n}}$ to the previous result, assuming that the errors are uncorrelated from one year to the next.

- The posterior standard deviations of the difference between fluxes from one year to the next (i.e., the error on the IAV for 2 consecutive years) is computed by applying an inflation factor of $\sqrt{2}$ to the previous result, still assuming that the errors are uncorrelated from one year to the next. We assume this approach to be a conservative hypothesis since, in reality, some of the transport and retrieval errors are recurrent, thereby inducing positive correlations and reducing the inflation factor.

The variability of $\mathrm{CH}_{4}$ concentrations depends on the oxidizing capacity of the atmosphere, which is largely controlled by $\mathrm{OH}$ concentrations. Since $\mathrm{OH}$ concentrations are constrained through MCF data in our multi-species inversion system (Sect. 2.1), the uncertainty on $\mathrm{OH}(\approx 5 \%$ after optimization) is accounted for in the uncertainty of the inferred $\mathrm{CH}_{4}$ emissions and of their inter-annual variations.

At a given space-time scale, the differences between the posterior errors of the three observing systems are mainly due to the constraints that each observing system brings on the flux estimates. This in turn is linked to the number of 


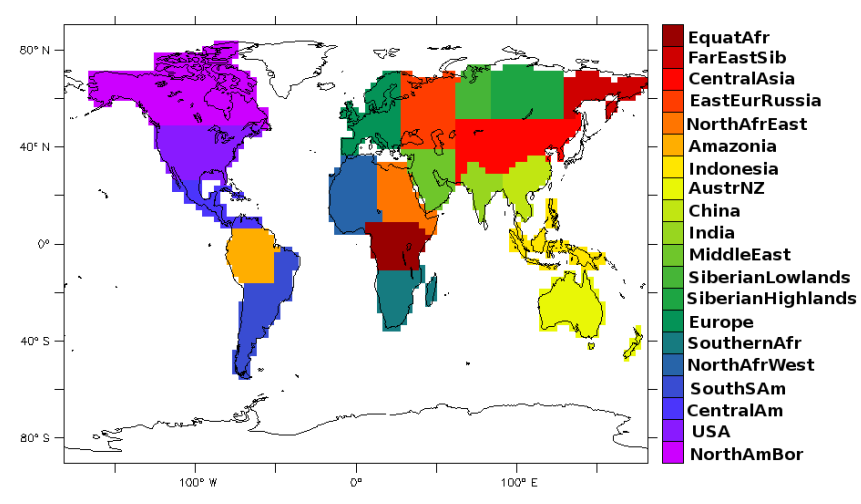

Figure 2. Regions on the model grid, adapted to key areas for methane fluxes.

data, to their distribution in time and space and also to their sensitivity to methane surface fluxes and to their uncertainty. It may also depend on the ability of the transport model to properly represent the various data.

\subsection{Evaluation criterion}

$\mathrm{CH}_{4}$ regional flux anomalies are defined here as the deviation from a reference of the $\mathrm{CH}_{4}$ inferred fluxes for various time periods, from the monthly to the 3-yearly scale. The reference is the 2004-2005 mean over the same time period. The aim of this definition is to get the order of magnitude of the year-to-year changes at various timescales. As the 20042005 reference corresponds to a period of minimum atmospheric methane growth rate (Dlugokencky et al., 2011), it leads to more positive anomalies for the longer timescales. The regional scale is based on the regions defined and shown in Fig. 2 and large latitudinal bands are defined as BorN for latitudes higher than $60^{\circ} \mathrm{N}$, MidN between 30 and $60^{\circ} \mathrm{N}$, TropN between 0 and $30^{\circ} \mathrm{N}$, TropS between 0 and $30^{\circ} \mathrm{S}$, MidS between 30 and $60^{\circ} \mathrm{S}$ and BorS higher than $60^{\circ} \mathrm{S}$. We study various spatial and temporal scales of inferred flux anomalies.

Our criterion consists in evaluating the ability of the observing systems to detect $\mathrm{CH}_{4}$ anomalies of a given amplitude, defined by the reference inversion. For this, we define a signal-to-noise ratio:

- The inversion with surface measurements is chosen to provide the signal as the data cover a long time window (2000-2011) as compared to the two other observing systems. This longer window makes it possible to sample the $\mathrm{CH}_{4}$ IAV more robustly than a 2-3-year inversion. We assume that the fluxes inferred by this inversion are representative of state-of-the art inversions currently published. The signal is actually the $\mathrm{CH}_{4}$ anomalies for the various timescales derived from REFSURF.

- For the three observing systems (SURF, IASI and GOSAT), the Bayesian posterior errors of the year-to- year changes of $\mathrm{CH}_{4}$ fluxes, computed from the Monte Carlo ensemble as described in Sect. 2.3, constitute the noise associated to each observing system.

Finally, the criterion for detecting $\mathrm{CH}_{4}$ anomalies is that the signal-to-noise ratio is larger than $1(\approx 68 \%$ confidence).

Comparing signal-to-noise ratios amounts to comparing noises normalized by the expected signals. The normalization provides an absolute criterion to assess the timescales and regions at which the $\mathrm{CH}_{4}$ anomalies are reliable. However, the quality of the chosen signal remains debatable and our diagnostic for GOSAT and IASI may be pessimistic in areas where SURF signal-to-noise ratio is low.

In the following, the presentation of the results is done for three timescales (seasonal, yearly and 3-yearly trends) before assessing their sensitivity to temporal and spatial aggregations.

\section{Results: signal-to-noise ratios}

\subsection{Seasonal-scale detection}

The signal-to-noise ratios are computed over 3-month periods (JFM, AMJ, JAS and OND, hereafter referred to as seasons for simplicity) from 2000 to 2011 , i.e., 48 occurrences (12 JFM, 12 AMJ, 12 JAS and 12 OND).

The three observing systems are able to detect almost all anomalies at the global scale (Table 1). As expected, the fraction of detected anomalies decreases with the spatial scale. At the global scale, $91-93 \%$ of the flux anomalies are detected depending on the observing system (Table 1). At semihemispheric scales (excluding MidS and BorS areas), this range is $0-87 \%$ (median $=49.5 \%$ ), GOSAT having the best range (8-87\%) compared to IASI (12-60\%) and SURF (0$66 \%$ ). The lack of detection in MidS and BorS is not significant considering the small methane fluxes involved. At the regional scale, the detection range is $0-79 \%$ (median $=4 \%$ ), with large contrasts. Again the range is more favorable for GOSAT $(0-79 \%$, median $=7 \%)$ than for SURF $(0-75 \%$, median $=3 \%)$ and IASI $(0-72 \%$, median $=0 \%)$. Anomalies in the USA, Central America (CentralAm), temperate Africa (SouthernAfr), Middle East, and Australia and New Zealand (AustrNZ) are not detected by any of the three observing systems. GOSAT is the only one of the three observing systems to detect any anomaly in temperate South America (SouthSAm) and northern Africa (NorthAfrWest, NorthAfrEast).

At the seasonal timescale, large signals are caused by various processes, depending on the emitting area. At high northern latitudes, a large seasonal cycle is expected for wetland emission areas, with mostly no emissions during winter and maximum emissions during summer; this leads to four seasons that are very different from their average and therefore also leads to large anomalies. The detection rate is above $50 \%$ for the three observing systems in this region (Ta- 
Table 1. Detection of the signal consisting in the anomalies at the seasonal timescale, i.e., quarters of the year (JFM, AMJ, JAS, OND). The signal is the difference between each quarter in the 2000-2011 period (i.e., 48 occurrences) and the 2004-2005 average from REFSURF. The noise is computed at the quarter timescale from each of the three observation systems, GOSAT, IASI and SURF. See Sects. 2.4 and 2.3 for details. In each cell of the table, we show $X \%(Y Y / Z Z)$ where $X \%$ is the percentage of quarterly anomalies detected (among 48 possible), $Y Y$ is the number of positive anomalies detected among the $Z Z$ detected anomalies. Column labeled Ave. mass indicates the average emitted mass of $\mathrm{CH}_{4}$ over 2004-2005 in the area.

\begin{tabular}{lrrrr}
\hline Region & Ave. mass $(\mathrm{Tg})$ & GOSAT & IASI & SURF \\
\hline Global & 517 & $93 \%(22 / 45)$ & $91 \%(21 / 44)$ & $91 \%(21 / 44)$ \\
BorN & 18 & $45 \%(10 / 22)$ & $39 \%(07 / 19)$ & $54 \%(12 / 26)$ \\
MidN & 177 & $77 \%(14 / 37)$ & $39 \%(12 / 19)$ & $70 \%(12 / 34)$ \\
TropN & 194 & $87 \%(22 / 42)$ & $60 \%(16 / 29)$ & $66 \%(17 / 32)$ \\
TropS & 115 & $08 \%(03 / 04)$ & $12 \%(04 / 06)$ & $\varnothing$ \\
MidS & 12 & $\varnothing$ & $\varnothing$ & $\varnothing$ \\
BorS & 1 & $\varnothing$ & $\varnothing$ & $\varnothing$ \\
NorthAmBor & 20 & $79 \%(14 / 38)$ & $58 \%(04 / 28)$ & $75 \%(12 / 36)$ \\
USA & 37 & $\varnothing$ & $\varnothing$ & $\varnothing$ \\
CentralAm & 17 & $\varnothing$ & $\varnothing$ & $\varnothing$ \\
Amazonia & 38 & $14 \%(01 / 07)$ & $06 \%(00 / 03)$ & $\varnothing$ \\
SouthSAm & 30 & $04 \%(00 / 02)$ & $\varnothing$ & $\varnothing$ \\
NorthAfrWest & 13 & $10 \%(05 / 05)$ & $\varnothing$ & $\varnothing$ \\
NorthAfrEast & 11 & $04 \%(02 / 02)$ & $\varnothing$ & $\varnothing(02)$ \\
AfrEquat & 32 & $22 \%(11 / 11)$ & $16 \%(08 / 08)$ & $02 \%(01 / 01)$ \\
SouthernAfr & 10 & $\varnothing$ & $\varnothing$ & \\
Europe & 33 & $06 \%(03 / 03)$ & $\varnothing$ & $04 \%(02 / 02)$ \\
EastEurRussia & 30 & $33 \%(12 / 16)$ & $\varnothing$ & $16 \%(08 / 08)$ \\
MiddleEast & 16 & $\varnothing$ & $\varnothing$ & \\
SiberianLowlands & 8 & $43 \%(10 / 21)$ & $02 \%(01 / 01)$ & $43 \%(10 / 21)$ \\
SiberianHighlands & 5 & $08 \%(04 / 04)$ & $04 \%(02 / 02)$ & $04 \%(02 / 02)$ \\
FarEastSib & 1 & $16 \%(08 / 08)$ & $08 \%(04 / 04)$ & $08 \%(04 / 04)$ \\
CentralAsia & 28 & $06 \%(03 / 03)$ & $\varnothing$ & $06 \%(03 / 03)$ \\
India & 50 & $56 \%(12 / 27)$ & $35 \%(05 / 17)$ & $25 \%(00 / 12)$ \\
China & 64 & $14 \%(03 / 07)$ & $04 \%(00 / 02)$ & $10 \%(01 / 05)$ \\
Indonesia & 36 & $06 \%(03 / 03)$ & $06 \%(03 / 03)$ & $04 \%(02 / 02)$ \\
AustrNZ & 6 & $\varnothing$ & $\varnothing$ & $\varnothing$ \\
\hline & & & $\varnothing$ \\
\hline
\end{tabular}

ble 1), but in contrast to the other regions and to the other timescales, the prior error statistics already lead to detection rates of $58 \%$ for the prior. This shows that the tropical IASI soundings do not add information for this region and at this timescale, as expected. GOSAT performs better by detecting more than three-quarters of the anomalies, about onethird of which are in winter (Fig. 3, due to almost null emissions when the surface is snow-covered), one-third in summer and one-third in fall (Fig. 3, due to maximum emissions in summer). Due to a larger noise $(\approx 1.5 \mathrm{Tg}$ vs. $\approx 1.2 \mathrm{Tg}$ for GOSAT, Fig. 4a), SURF misses all springs (Fig. 3). In the larger BorN area, only winter and summer are detected (Fig. 3).

In the tropics, some areas also have large seasonal variations, mainly due to biomass burning or rice-paddies. In AfrEquat, some of the AMJ positive signals generated are detected by GOSAT and IASI (Fig. 4a). Note that SURF performs poorly in this area (Table 1) due to the lack of stations, which leads to large noise $(\approx 3.3 \mathrm{Tg}$, Fig. $4 \mathrm{a})$. In In- dia and China, rice-paddy practices led to a seasonal cycle of methane emissions with a maximum in JAS and a minimum in JFM (Matthews et al., 1991). The three systems detect anomalies in JFM and JAS (Fig. 3) with consistent signs $(\approx$ half positive, half negative anomalies) for GOSAT, negative anomalies preferentially detected by IASI and SURF (Table 1).

\subsection{Yearly-scale detection}

The signal-to-noise ratios are computed for each year from 2000 to 2011 , i.e., 12 occurrences. At the yearly scale, detection rates are smaller than at the seasonal scale, at all spatial scales. Note that most anomalies are positive since the reference for computing the signal is 2004-2005, i.e., the period of global minimum over 2000-2011. At the global scale, detection rates range from 58 to $75 \%$ (Table 2). The boreal zone (BorN) is not detected, whereas the tropics (TropN and TropS) remain the best detected zone (16-50\%). At the regional scale, the detection rates range between 0 and $33 \%$ 

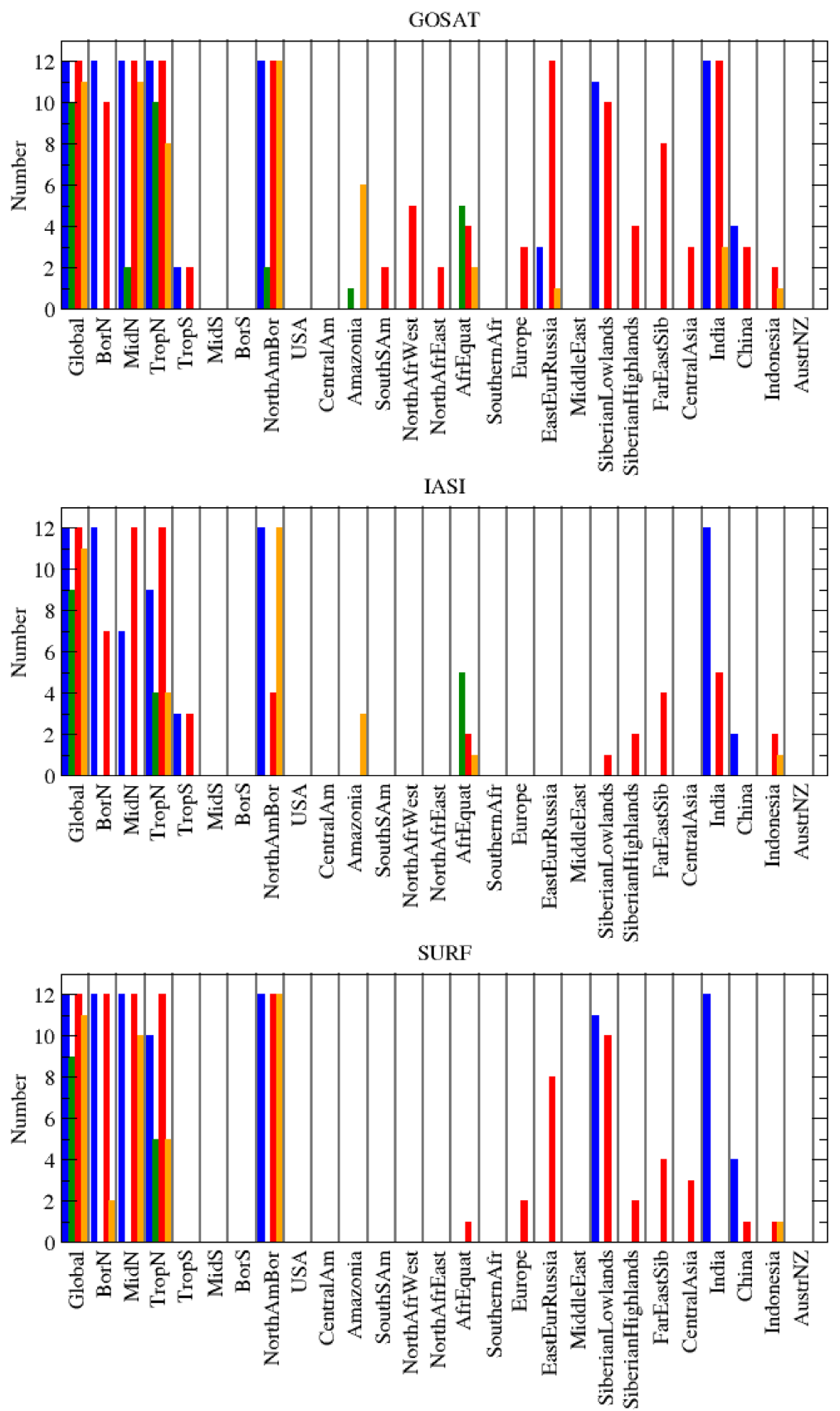

Figure 3. Number of detected seasons over the 12 possible for winter (JFM, blue), spring (AMJ, green), summer (JAS, red) and fall (OND, orange) in the various regions.

with a median of $0 \%$; the only regions above $25 \%$ of detection are tropical Africa (AfrEquat) and NorthAfrWest for GOSAT. No detection is obtained in key regions for methane emissions such as Amazonia (except GOSAT at $8 \%$ ), India, China and North America (NorthAmBor, USA).

The differences between the three observing systems are larger at the yearly scale than at the seasonal scale: GOSAT and IASI detect $75 \%$ of the 12 possible global occurrences vs. $58 \%$ for SURF (Table 2). At the regional scale, GOSAT detects more anomalies than the two other systems. Indeed, GOSAT noises are smaller than the two other systems $(<3.5 \mathrm{Tg}$ in AfrEquat for GOSAT against $>3.5 \mathrm{Tg}$ for IASI and $>5.8$ for SURF; $<2.5 \mathrm{Tg}$ in NorthAfrWest for GOSAT against $>4.7 \mathrm{Tg}$ for IASI and SURF). This is partly due to the large number of data available in these two regions (Table A1); with NorthAfrEast, NorthAfrWest has the largest number of GOSAT and IASI data, mainly because it is among the driest areas, i.e., with the lowest cloud cover. 

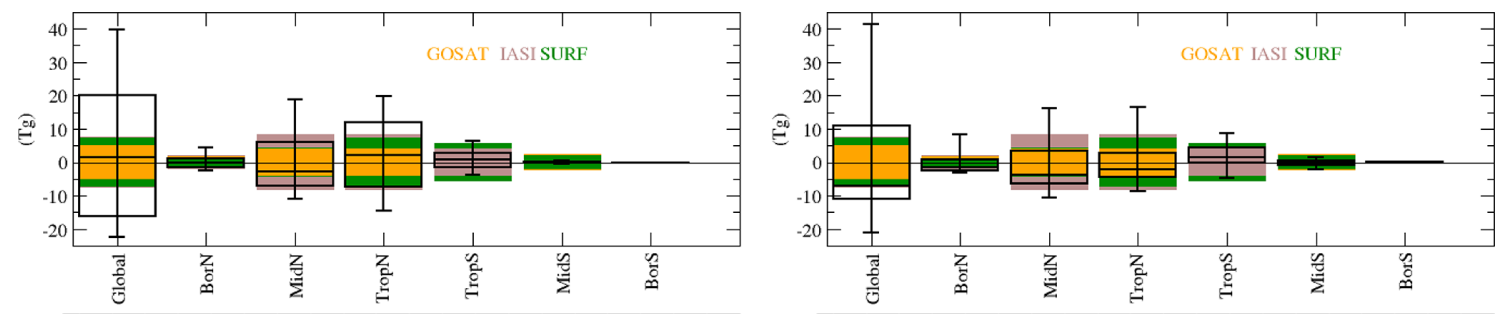

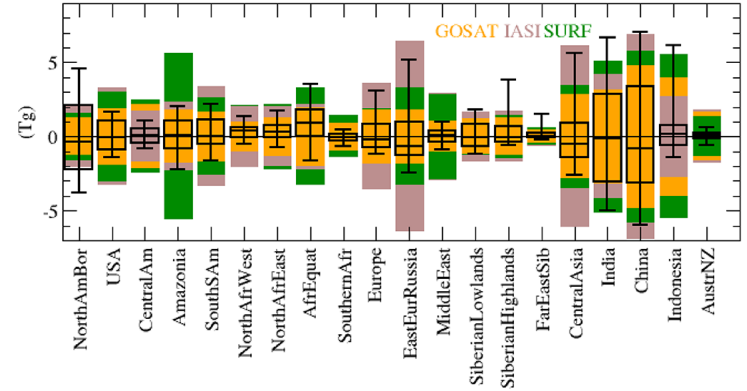

(a) Signal REFSURF

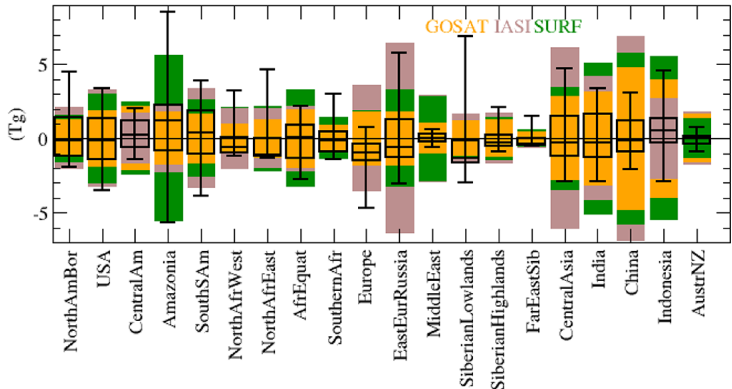

(b) Signal PBSURF

Figure 4. Noise at the seasonal timescale by the three observing systems (bars) and box plots (median, 25 and $75 \%$ ) for the signal in various areas (latitudinal bands and regions). Detection is achieved when the signal is larger than the noise, i.e., for all the occurrences in each box plot which lay outside the matching colored bar.

In agreement with the intuition of Bergamaschi et al. (2013) that performing gross averages makes it possible to extract a signal from the inversion, the detection is enhanced in the latitudinal bands, e.g., detection rates $\geq 25 \%$ in TropN for GOSAT and SURF. But it remains difficult to robustly extract yearly flux anomalies. Therefore, we now focus our analysis on longer timescales, with a longer time aggregation of 3 years, to get hints at the longer trends in methane emissions.

\subsection{Trend detection over 2000-2011}

To study the detection of flux long-term trend over 12 years, a compromise has to be found between the rather short length of this time window and the time aggregation of fluxes, which needs to filter out year-to-year changes. Aggregating through time while still retaining a small-enough resolution to discuss trends over 2000-2011, we define four time windows of 3 years each: 2000-2002, 2003-2005, 2006-2008 and 2009-2011. The reference period for the definition of the anomalies of each of these four periods is still 2004-2005 (Sect. 2.4).

At the global scale, the emissions have slowly decreased from 2000 to 2005, with a global minimum in 2004-2005, then increased at a larger rate after 2006 (Kirschke et al., 2013). The three observing systems are able to detect the large positive anomalies after 2006 and detect nothing before (Table 3). The three observing systems are able to detect the same temporal evolution of the signal in TropN and TropS. Only GOSAT and SURF detect MidN anomalies; the lower detection by IASI at these latitudes is expected since the data used here are only within $\pm 30^{\circ}$ of the Equator (Table A1, no IASI data in MidN). The signal in BorN is never detected.
This is consistent with the recent increase of methane global emissions coming mostly from the tropics and to a lesser extent from the northern midlatitudes, as suggested by Bergamaschi et al. (2013) and Nisbet et al. (2014).

Being able to detect anomalies at a smaller spatial scale could help attributing the changes in methane emissions to particular processes. Unfortunately, even when aggregating 3 years together (instead of 1 year as in Sect. 3.2), it is still difficult to detect regional anomalies.

In TropN, among the regions with a good detection rate are NorthAfrWest and NorthAfrEast plus some of AfrEquat, the remainder of this region being in TropS. In these regions, all three observing systems detect anomalies, even though GOSAT has the largest signal-to-noise ratios. Note that SURF seems to benefit from the stations located mostly on the coasts (only ASK is actually inland). GOSAT is also able to detect negative (2000-2003) and positive (20062011) anomalies in MiddleEast; SURF is under the detection threshold because the available station in the region, WIS, is upwind the area and no other station is available close enough downwind; the anomalies are not detected by IASI either because IASI weighting function peaks in the middle troposphere. In a region dominated by subsidence, like MiddleEast, the altitude concentrations seen by IASI are not directly connected to the surface. The detection of surface variations in the fluxes is therefore poor, contrary to regions dominated by convection like Indonesia, where IASI has the best detection rates. In Indonesia, IASI and GOSAT agree on detectable positive anomalies in 2000-2002 and nothing detectable for 2003-2005 and 2009-2011. Indeed, no large El Niño occurred during the first decade of the 21 st century with 
Table 2. Detection of the signal consisting in the anomalies at the yearly timescale. The signal is the difference between each year in the 2000-2011 period (i.e., 12 occurrences) and the 2004-2005 average from REFSURF. The noise is computed at the yearly timescale from each of the three observation systems, GOSAT, IASI and SURF. See Sects. 2.4 and 2.3 for details. In each cell of the table, we show $X \%$ $(Y Y / Z Z)$ where $X \%$ is the percentage of yearly anomalies detected (among 12 possible), $Y Y$ is the number of positive anomalies detected among the $Z Z$ detected anomalies. Column labeled Ave. mass indicates the average emitted mass of $\mathrm{CH}_{4}$ over 2004-2005 in the area.

\begin{tabular}{lrrrr}
\hline Region & Ave. mass (Tg) & GOSAT & IASI & SURF \\
\hline Global & 517 & $75 \%(08 / 09)$ & $75 \%(08 / 09)$ & $58 \%(07 / 07)$ \\
BorN & 18 & $\varnothing$ & $\varnothing$ & $\varnothing$ \\
MidN & 177 & $08 \%(01 / 01)$ & $\varnothing$ & $08 \%(01 / 01)$ \\
TropN & 194 & $50 \%(06 / 06)$ & $\varnothing$ & $25 \%(03 / 03)$ \\
TropS & 115 & $16 \%(02 / 02)$ & $16 \%(02 / 02)$ & $16 \%(02 / 02)$ \\
MidS & 12 & $\varnothing$ & $\varnothing$ & $\varnothing$ \\
BorS & 1 & $\varnothing$ & $\varnothing$ & $\varnothing$ \\
NorthAmBor & 20 & $\varnothing$ & $\varnothing$ & $\varnothing$ \\
USA & 37 & $\varnothing$ & $\varnothing$ & $\varnothing$ \\
CentralAm & 17 & $\varnothing$ & $\varnothing$ & $\varnothing$ \\
Amazonia & 38 & $08 \%(00 / 01)$ & $\varnothing$ & $\varnothing$ \\
SouthSAm & 30 & $\varnothing$ & $\varnothing$ & $\varnothing$ \\
NorthAfrWest & 13 & $33 \%(04 / 04)$ & $\varnothing$ & $\varnothing$ \\
NorthAfrEast & 11 & $08 \%(01 / 01)$ & $\varnothing$ & $\varnothing$ \\
AfrEquat & 32 & $33 \%(04 / 04)$ & $\varnothing 3 \%(04 / 04)$ & $25 \%(03 / 03)$ \\
SouthernAfr & 10 & $\varnothing$ & $\varnothing$ & $\varnothing$ \\
Europe & 33 & $16 \%(02 / 02)$ & $\varnothing$ & $\varnothing$ \\
EastEurRussia & 30 & $\varnothing$ & $\varnothing$ & $\varnothing$ \\
MiddleEast & 16 & $\varnothing$ & $\varnothing$ & $\varnothing$ \\
SiberianLowlands & 8 & $\varnothing$ & $\varnothing$ & $\varnothing$ \\
SiberianHighlands & 5 & $08 \%(01 / 01)$ & $\varnothing$ & $\varnothing$ \\
FarEastSib & 1 & $08 \%(01 / 01)$ & $\varnothing$ & $\varnothing$ \\
CentralAsia & 28 & $08 \%(00 / 01)$ & $\varnothing$ & $\varnothing$ \\
India & 50 & $\varnothing$ & $\varnothing$ & $\varnothing$ \\
China & 64 & $16 \%(02 / 02)$ & $16 \%(02 / 02)$ & $\varnothing$ \\
Indonesia & 36 & $\varnothing$ & $\varnothing$ & $\varnothing$ \\
AustrNZ & & $\varnothing$ & $\varnothing$ \\
\hline & 16 & $\varnothing$ & $\varnothing$ \\
\hline
\end{tabular}

the associated large fires, such as those experienced in 19971998 or more recently in 2015-2016, for instance (National Weather Service - Climate Prediction Center, 2016).

Among the key areas for methane emissions, signals in Amazonia (dominated by tropical wetlands) and in BorN, particularly in SiberianLowlands (dominated by boreal wetlands in summer), remain undetectable by the three systems. In SiberianLowlands, the noises of the three systems are small (between 3.8 and 7.8 Tg (not shown)); in Amazonia, the noises of the satellites are relatively small $(\approx 6$ and $\approx 7 \mathrm{Tg}$, respectively, for GOSAT and IASI), whereas the noise of SURF, for which no stations are available closer than ASC in the Atlantic, is $\approx 24 \mathrm{Tg}$ (Fig. 7, 3Y case). Nevertheless, all these anomalies remain smaller than the smaller noise, and are therefore not detectable in our framework. This is because the signal variability remains small after inversion (less than $20 \%$ of the average mass over 2004-2005). Possible reasons for this are an actual low variability in these regions for this period and the fact that the choice to limit IAV in the prior emissions to biomass burning together with the lack of constraints from the atmosphere led the inferred fluxes to stick to the low IAV prior.

\subsection{Detection at other timescales}

As shown previously, the temporal scale at which the signal and noise are computed has an impact on the detection: 3-monthly (seasonal, Sect. 3.1) and yearly (year-to-year changes, Sect. 3.3) timescales over a 12-year time window; 3 -yearly timescale in 3-year time windows (trend, Sect. 3.3). We investigate the impact of the timescale of flux aggregation within the 3-year time windows of Sect. 3.3 on the noise and the signal for three areas: global (Fig. 5), the northern tropics (Fig. 6) and Amazonia (Fig. 7). For each area, we perform time aggregations from 3-yearly to monthly scales; the 3-yearly case corresponds to the results commented in Sect. 3.3 about trend. At all spatial scales, the noises and signals are smaller when the timescale is smaller (from 3-yearly to monthly). As expected for emissions with seasonal cycles, the seasonal (4- or 3-monthly) scale is particularly detected (Figs. 5, 6) in our relatively large areas. 
Table 3. Detection of the signal consisting in the anomalies at the 3-yearly timescale. The signal is the difference between each 3-year time window in the 2000-2011 period (2000-2002, 2003-2005, 2006-2008, 2009-2011) and the 2004-2005 average from REFSURF. The noise is computed at the 3-yearly timescale from each of the three observation systems, GOSAT, IASI and SURF. See Sects. 2.4 and 2.3 for details. In each cell of the table, we show whether a positive anomaly, a negative anomaly or no anomaly is detected and with which signal-to-noise ratio: positive anomaly detected: $+++=\operatorname{stn}$ ratio $>3,++=\operatorname{stn}$ ratio $>2$ and $+=\operatorname{stn}$ ratio $>1$; negative anomaly detected with $--=$ stn ratio $<-2,-=\operatorname{stn}$ ratio $<-2, \varnothing,=$ no anomaly detected. The number below the name of the area is the average emitted mass of $\mathrm{CH}_{4}$ over 2004-2005 in the area.

\begin{tabular}{|c|c|c|c|c|c|}
\hline Region & System & 2000-2002 & 2003-2005 & 2006-2008 & 2009-2011 \\
\hline Global & GOSAT & $\varnothing$ & $\varnothing$ & +++ & +++ \\
\hline \multirow[t]{2}{*}{517} & IASI & $\varnothing$ & $\varnothing$ & +++ & +++ \\
\hline & SURF & $\varnothing$ & $\varnothing$ & +++ & +++ \\
\hline BorN & GOSAT & $\varnothing$ & $\varnothing$ & $\varnothing$ & $\varnothing$ \\
\hline \multirow[t]{2}{*}{18} & IASI & $\varnothing$ & $\varnothing$ & $\varnothing$ & $\varnothing$ \\
\hline & SURF & $\varnothing$ & $\varnothing$ & $\varnothing$ & $\varnothing$ \\
\hline MidN & GOSAT & $\varnothing$ & $\varnothing$ & + & + \\
\hline \multirow[t]{2}{*}{177} & IASI & $\varnothing$ & $\varnothing$ & $\varnothing$ & $\varnothing$ \\
\hline & SURF & $\varnothing$ & $\varnothing$ & + & + \\
\hline TropN & GOSAT & $\varnothing$ & $\varnothing$ & ++ & +++ \\
\hline \multirow[t]{2}{*}{194} & IASI & $\varnothing$ & $\varnothing$ & + & + \\
\hline & SURF & $\varnothing$ & $\varnothing$ & + & + \\
\hline TropS & GOSAT & $\varnothing$ & $\varnothing$ & $\varnothing$ & + \\
\hline \multirow[t]{2}{*}{115} & IASI & + & $\varnothing$ & $\varnothing$ & + \\
\hline & SURF & $\varnothing$ & $\varnothing$ & $\varnothing$ & + \\
\hline MidS & GOSAT & $\varnothing$ & $\varnothing$ & $\varnothing$ & $\varnothing$ \\
\hline \multirow{2}{*}{12} & IASI & $\varnothing$ & $\varnothing$ & $\varnothing$ & $\varnothing$ \\
\hline & SURF & $\varnothing$ & $\varnothing$ & $\varnothing$ & $\varnothing$ \\
\hline \multirow{3}{*}{$\begin{array}{l}\text { BorS } \\
1\end{array}$} & GOSAT & $\varnothing$ & $\varnothing$ & $\varnothing$ & $\varnothing$ \\
\hline & IASI & $\varnothing$ & $\varnothing$ & $\varnothing$ & $\varnothing$ \\
\hline & SURF & $\varnothing$ & $\varnothing$ & $\varnothing$ & $\varnothing$ \\
\hline \multirow{3}{*}{$\begin{array}{l}\text { NorthAmBor } \\
20\end{array}$} & GOSAT & $\varnothing$ & $\varnothing$ & $\varnothing$ & $\varnothing$ \\
\hline & IASI & $\varnothing$ & $\varnothing$ & $\varnothing$ & $\varnothing$ \\
\hline & SURF & $\varnothing$ & $\varnothing$ & $\varnothing$ & $\varnothing$ \\
\hline \multirow{3}{*}{$\begin{array}{l}\text { USA } \\
37\end{array}$} & GOSAT & $\varnothing$ & $\varnothing$ & $\varnothing$ & $\varnothing$ \\
\hline & IASI & $\varnothing$ & $\varnothing$ & $\varnothing$ & $\varnothing$ \\
\hline & SURF & $\varnothing$ & $\varnothing$ & $\varnothing$ & $\varnothing$ \\
\hline \multirow{3}{*}{$\begin{array}{l}\text { CentralAm } \\
17\end{array}$} & GOSAT & $\varnothing$ & $\varnothing$ & $\varnothing$ & $\varnothing$ \\
\hline & IASI & $\varnothing$ & $\varnothing$ & $\varnothing$ & $\varnothing$ \\
\hline & SURF & $\varnothing$ & $\varnothing$ & $\varnothing$ & $\varnothing$ \\
\hline \multirow{3}{*}{$\begin{array}{l}\text { Amazonia } \\
38\end{array}$} & GOSAT & $\varnothing$ & $\varnothing$ & $\varnothing$ & $\varnothing$ \\
\hline & IASI & $\varnothing$ & $\varnothing$ & $\varnothing$ & $\varnothing$ \\
\hline & SURF & $\varnothing$ & $\varnothing$ & $\varnothing$ & $\varnothing$ \\
\hline \multirow{3}{*}{$\begin{array}{l}\text { SouthSAm } \\
30\end{array}$} & GOSAT & $\varnothing$ & $\varnothing$ & $\varnothing$ & + \\
\hline & IASI & $\varnothing$ & $\varnothing$ & $\varnothing$ & $\varnothing$ \\
\hline & SURF & $\varnothing$ & $\varnothing$ & $\varnothing$ & $\varnothing$ \\
\hline \multirow{3}{*}{$\begin{array}{l}\text { NorthAfrWest } \\
13\end{array}$} & GOSAT & $\varnothing$ & $\varnothing$ & + & ++ \\
\hline & IASI & $\varnothing$ & $\varnothing$ & $\varnothing$ & + \\
\hline & SURF & $\varnothing$ & $\varnothing$ & $\varnothing$ & + \\
\hline \multirow{3}{*}{$\begin{array}{l}\text { NorthAfrEast } \\
11\end{array}$} & GOSAT & $\varnothing$ & $\varnothing$ & + & + \\
\hline & IASI & $\varnothing$ & $\varnothing$ & + & + \\
\hline & SURF & $\varnothing$ & $\varnothing$ & + & + \\
\hline
\end{tabular}


Table 3. Continued.

\begin{tabular}{|c|c|c|c|c|c|}
\hline Region & System & 2000-2002 & 2003-2005 & 2006-2008 & 2009-2011 \\
\hline \multirow{3}{*}{$\begin{array}{l}\text { AfrEquat } \\
32\end{array}$} & GOSAT & & $\varnothing$ & ++ & +++ \\
\hline & IASI & $\varnothing$ & $\varnothing$ & ++ & +++ \\
\hline & SURF & $\varnothing$ & $\varnothing$ & + & ++ \\
\hline \multirow{3}{*}{$\begin{array}{l}\text { SouthernAfr } \\
10\end{array}$} & GOSAT & $\varnothing$ & $\varnothing$ & $\varnothing$ & $\varnothing$ \\
\hline & IASI & $\varnothing$ & $\varnothing$ & $\varnothing$ & $\varnothing$ \\
\hline & SURF & $\varnothing$ & $\varnothing$ & $\varnothing$ & $\varnothing$ \\
\hline \multirow{3}{*}{$\begin{array}{l}\text { Europe } \\
33\end{array}$} & GOSAT & + & $\varnothing$ & $\varnothing$ & $\varnothing$ \\
\hline & IASI & $\varnothing$ & $\varnothing$ & $\varnothing$ & $\varnothing$ \\
\hline & SURF & + & $\varnothing$ & $\varnothing$ & $\varnothing$ \\
\hline \multirow{3}{*}{$\begin{array}{l}\text { EastEurRussia } \\
30\end{array}$} & GOSAT & $\varnothing$ & $\varnothing$ & $\varnothing$ & $\varnothing$ \\
\hline & IASI & $\varnothing$ & $\varnothing$ & $\varnothing$ & $\varnothing$ \\
\hline & SURF & $\varnothing$ & $\varnothing$ & $\varnothing$ & $\varnothing$ \\
\hline \multirow{3}{*}{$\begin{array}{l}\text { MiddleEast } \\
16\end{array}$} & GOSAT & - & $\varnothing$ & $\varnothing$ & + \\
\hline & IASI & $\varnothing$ & $\varnothing$ & $\varnothing$ & $\varnothing$ \\
\hline & SURF & $\varnothing$ & $\varnothing$ & $\varnothing$ & $\varnothing$ \\
\hline \multirow{3}{*}{$\begin{array}{l}\text { SiberianLowlands } \\
8\end{array}$} & GOSAT & $\varnothing$ & $\varnothing$ & $\varnothing$ & $\varnothing$ \\
\hline & IASI & $\varnothing$ & $\varnothing$ & $\varnothing$ & $\varnothing$ \\
\hline & SURF & $\varnothing$ & $\varnothing$ & $\varnothing$ & $\varnothing$ \\
\hline \multirow{3}{*}{$\begin{array}{l}\text { SiberianHighlands } \\
5\end{array}$} & GOSAT & $\varnothing$ & $\varnothing$ & $\varnothing$ & $\varnothing$ \\
\hline & IASI & $\varnothing$ & $\varnothing$ & $\varnothing$ & $\varnothing$ \\
\hline & SURF & $\varnothing$ & $\varnothing$ & $\varnothing$ & $\varnothing$ \\
\hline \multirow{3}{*}{$\begin{array}{l}\text { FarEastSib } \\
1\end{array}$} & GOSAT & + & $\varnothing$ & $\varnothing$ & $\varnothing$ \\
\hline & IASI & $\varnothing$ & $\varnothing$ & $\varnothing$ & $\varnothing$ \\
\hline & SURF & $\varnothing$ & $\varnothing$ & $\varnothing$ & $\varnothing$ \\
\hline \multirow{3}{*}{$\begin{array}{l}\text { CentralAsia } \\
28\end{array}$} & GOSAT & - & $\varnothing$ & $\varnothing$ & $\varnothing$ \\
\hline & IASI & $\varnothing$ & $\varnothing$ & $\varnothing$ & $\varnothing$ \\
\hline & SURF & $\varnothing$ & $\varnothing$ & $\varnothing$ & $\varnothing$ \\
\hline \multirow{3}{*}{$\begin{array}{l}\text { India } \\
50\end{array}$} & GOSAT & $\varnothing$ & $\varnothing$ & $\varnothing$ & $\varnothing$ \\
\hline & IASI & $\varnothing$ & $\varnothing$ & $\varnothing$ & $\varnothing$ \\
\hline & SURF & $\varnothing$ & $\varnothing$ & $\varnothing$ & $\varnothing$ \\
\hline \multirow{3}{*}{$\begin{array}{l}\text { China } \\
64\end{array}$} & GOSAT & $\varnothing$ & $\varnothing$ & $\varnothing$ & $\varnothing$ \\
\hline & IASI & - & $\varnothing$ & $\varnothing$ & $\varnothing$ \\
\hline & SURF & $\varnothing$ & $\varnothing$ & $\varnothing$ & $\varnothing$ \\
\hline \multirow{3}{*}{$\begin{array}{l}\text { Indonesia } \\
36\end{array}$} & GOSAT & + & $\varnothing$ & $\varnothing$ & $\varnothing$ \\
\hline & IASI & + & $\varnothing$ & + & $\varnothing$ \\
\hline & SURF & $\varnothing$ & $\varnothing$ & $\varnothing$ & $\varnothing$ \\
\hline \multirow{3}{*}{$\begin{array}{l}\text { AustrNZ } \\
6\end{array}$} & GOSAT & $\varnothing$ & $\varnothing$ & $\varnothing$ & $\varnothing$ \\
\hline & IASI & $\varnothing$ & $\varnothing$ & $\varnothing$ & $\varnothing$ \\
\hline & SURF & $\varnothing$ & $\varnothing$ & $\varnothing$ & $\varnothing$ \\
\hline
\end{tabular}

In key region Amazonia (Fig. 7), no signal is detected at the 3-yearly timescale nor at the monthly timescale by any of the three systems; only GOSAT detects about $8 \%$ of the anomalies at the yearly timescale. Actually, the timescale at which the best detection rates are found depends on the region and varies from the largest possible (3-year scale) to the 2-month scale. In Africa (NorthAfrWest, NorthAfrEast,
AfrEquat, SouthernAfr), the best detection rates are obtained at the 3-year scale by all three systems, as in Europe, Indonesia, and Australia and New Zealand (AustrNZ). In the north of Eurasia (EastEurRussia, SiberianLowlands, SiberianHighlands, FarEastSib), the best detection rates range from the 3 -yearly to the 3-monthly timescales. In CentralAsia, IASI obtains the best detection rates at the 2-monthly timescale. 


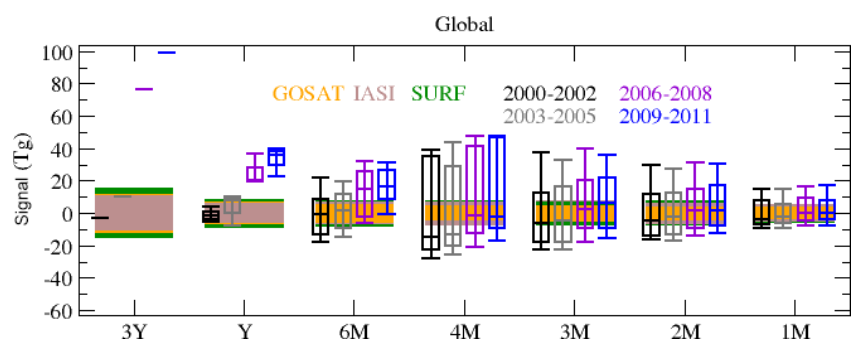

Figure 5. Impact of temporal aggregation on noise (bars) and signal (box plots with median, 25 and $75 \%$ ) over 3-year time windows. Detection is achieved when the signal is larger than the noise, i.e., for all the occurrences in each box plot which lay outside the matching colored bar. Link to Table 3: the Global lines of the table corresponds to the $3 \mathrm{Y}$ bars here.

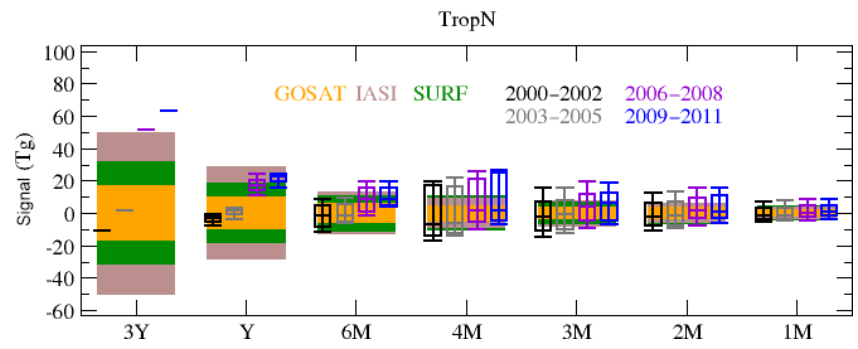

Figure 6. Impact of temporal aggregation on noise (bars) and signal (box plots with median, 25 and $75 \%$ ) over 3-year time windows. Detection is achieved when the signal is larger than the noise, i.e., for all the occurrences in each box plot which lay outside the matching colored bar. Link to Table 3: the TropN lines of the table corresponds to the $3 \mathrm{Y}$ bars here.

At high latitudes (NorthAmBor), the best detection rates are found at the 2-monthly (SURF), 3-monthly (IASI) and 4monthly (GOSAT) timescales (with $88-100 \%$ for GOSAT, up to $75 \%$ for IASI (but which is not better than the prior detection rate, see Sect. 3.1) and up to $77 \%$ for SURF), which is consistent with seasonal cycles with a large magnitude over a short period of time in this region.

In order to further understand the various levels of detection described above, we investigate the sensitivity of our results to two main parameters of our setup: spatial aggregation and signal used.

\section{Sensitivity analysis}

\subsection{Impact of spatial aggregation on trend detection}

Our inversion system solves for methane fluxes at model resolution $\left(3.75^{\circ} \times 2.5^{\circ}\right)$ worldwide. Although spatial and temporal correlations are prescribed (see Sect. 2.3), flux anomalies of different signs may still be obtained. These anomalies may be either the realistic result of the constraints or due to the optimization taking an easy path when too few con-

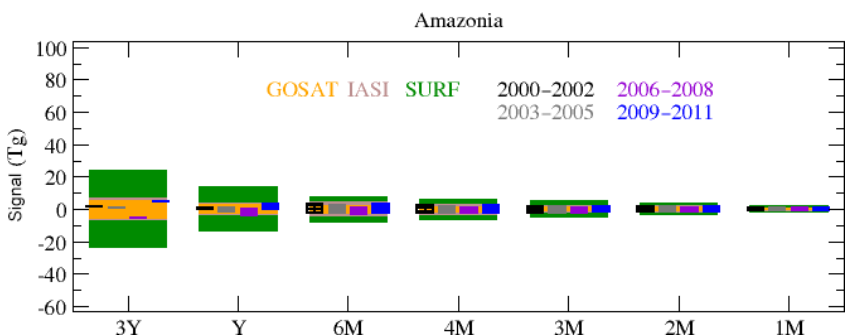

Figure 7. Impact of temporal aggregation on noise (bars) and signal (box plots with median, 25 and $75 \%$ ) over 3-year time windows. Detection is achieved when the signal is larger than the noise, i.e., for all the occurrences in each box plot which lay outside the matching colored bar. Link to Table 3: the Amazonia lines of the table corresponds to the $3 \mathrm{Y}$ bars here.

straints are available. The definition of larger areas may lead to summing up anomalies of opposite signs and hide (realistic or not) spatial variations. We try here to investigate the impact of the spatial aggregation of model pixels in the case of one illustrative region, Amazonia, which is a key area for methane emissions and remains poorly detected by all the studied observing systems at all timescales (see Sect. 3.4). In the region, as defined on our model grid, the signal at the pixel scale is indeed patchy (Fig. 8). Dipoles of negative/positive signal are summed up when aggregating at regional scale. The impact of the progressive aggregation of rings of pixels from the center of Amazonia is displayed in Fig. 9 for the 3-yearly timescale; the signal is detected by all systems for the four 3 -year periods up to the third ring, i.e., for a region covering 25 pixels instead of 66 . It would then be possible to define the regions based on the spatial aggregation that allows the best detection rates for the chosen observing system. Nevertheless, this may be inconsistent with users' needs, e.g., if they are expressed in terms of country-based budgets.

\subsection{Impact of the signal on seasonal and yearly detection}

Since the signal is obtained from one inversion only, it depends on a series of assumptions (error statistics, data selection, etc.) and may have large uncertainties in various areas (e.g., far from the observing stations). Another signal definition is therefore tested. We choose an inversion by Bousquet et al. (2011), (called PBSURF hereafter) instead of the REFSURF inversion described above. Like REFSURF, PBSURF covers enough years of analysis to be representative of the variability of methane fluxes. The main differences between PBSURF and REFSURF are as follows:

- PBSURF uses an analytical inversion, whereas REFSURF is variational. 

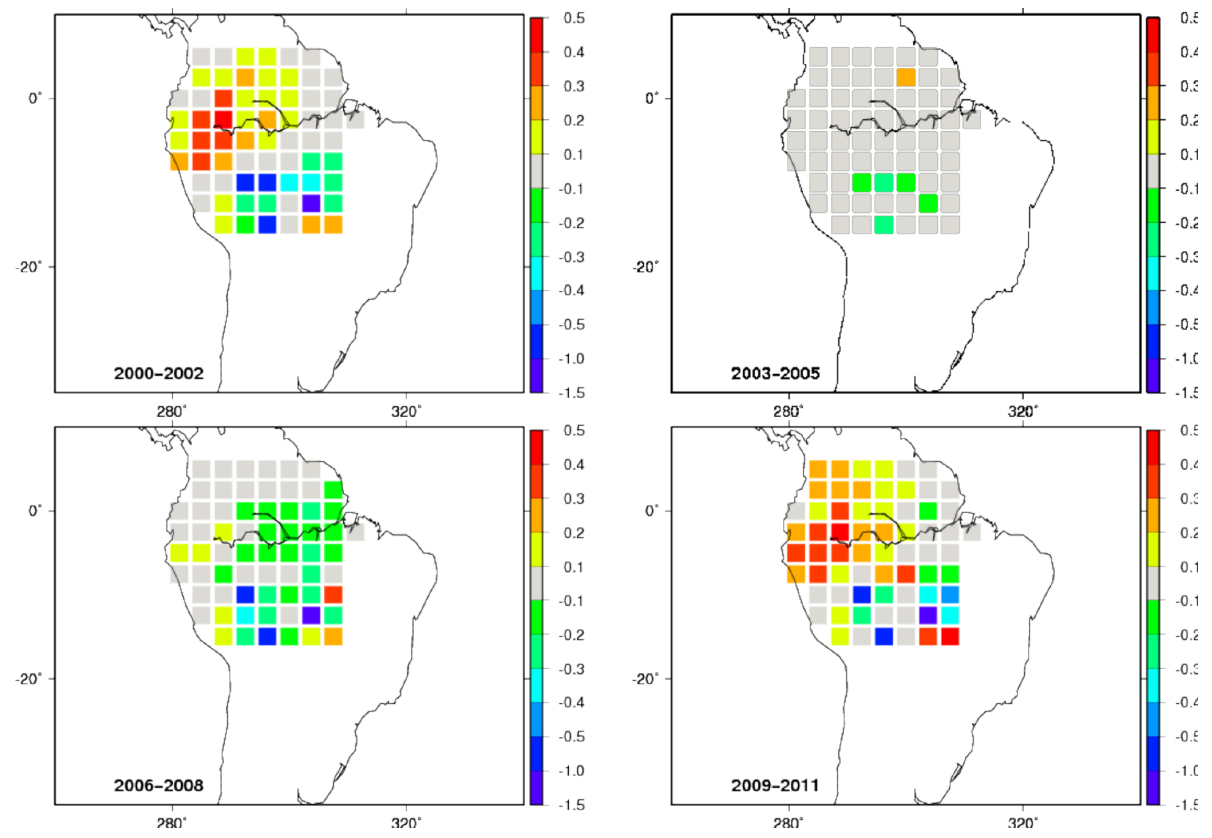

Figure 8. Signal (Tg) for the four 3-year time windows at the pixel scale.

- Because of this, PBSURF solves for methane fluxes for large regions, whereas REFSURF works at the pixel scale.

- PBSURF retrieves monthly fluxes, whereas REFSURF retrieves fluxes at a weekly resolution.

- PBSURF solves for methane fluxes for several processes in each region, whereas REFSURF solves for net emissions.

- As a consequence of the three previous points, the B matrices of the two inversions are quite different.

- PBSURF uses monthly means of the surface observations as constraints, whereas REFSURF uses hourly data.

- Because of this, the sets of surface stations used by PBSURF and REFSURF are different.

The large-region-scale inversion means that the spatial variability of the prior is kept within each region and is only scaled (contrary to REFSURF, which is performed at the pixel scale, i.e., is able to vary only a few pixels to match the data). This difference in the methods may lead to very different spatial variability in each of the regions of interest (Fig. 4), a larger variability allowing a better detection rate with our criterion. Indeed, the large-region-scale inversion may lead to larger variability than pixel-based inversions in some regions (e.g., Pison et al. (2013)) because of the homothetic scaling of the pixels composing each region in PBSURF (correlations of 1 between pixels) as opposed to the individual scaling of model pixels with soft constraints in REFSURF (spatial correlations less than 1).

We first focus on the seasonal (3-monthly) scale, which is the timescale at which the detection is the most favorable in the largest areas (Sect. 3.4) while being relevant for methane emissions at the regional scale defined here. The issue here is not whether the two inversions agree on the retrieved fluxes but whether the detection rates differ. Europe illustrates how the detection rates of two signals can differ; for GOSAT, signal PBSURF is more than twice as often detected as REFSURF and the signs of the detected anomalies are opposite (positive for REFSURF, mostly negative with PBSURF, Tables 1 and A2; less positive anomalies are detected for a larger total number of detected anomalies).

Signal PBSURF contains more negative anomalies than REFSURF at the global scale and in MidN and TropN. This is due to the fact that the 2 years of global minimum in PBSURF are not 2004 and 2005 but 2004 and 2006, so that using 2004-2005 as the reference period does not lead to mainly positive anomalies. For the three observing systems, detection is better with signal PBSURF in the Southern Hemisphere tropics (TropS). In the Northern Hemisphere, at the regional scale, the detection rate is shifted in longitude. NorthAmBor seasons are about $25 \%$ less often detected, whereas up to 30 times more occurrences are detected in SiberianLowlands, SiberianHighlands and FarEastSib. In SiberianLowlands and FarEastSib, the larger number is due to negative signals for GOSAT and SURF. The same pattern is seen in the midlatitudes where MiddleEast, India and China, which are almost never detected with signal PBSURF (only India for GOSAT), vs. NorthAfrWest 

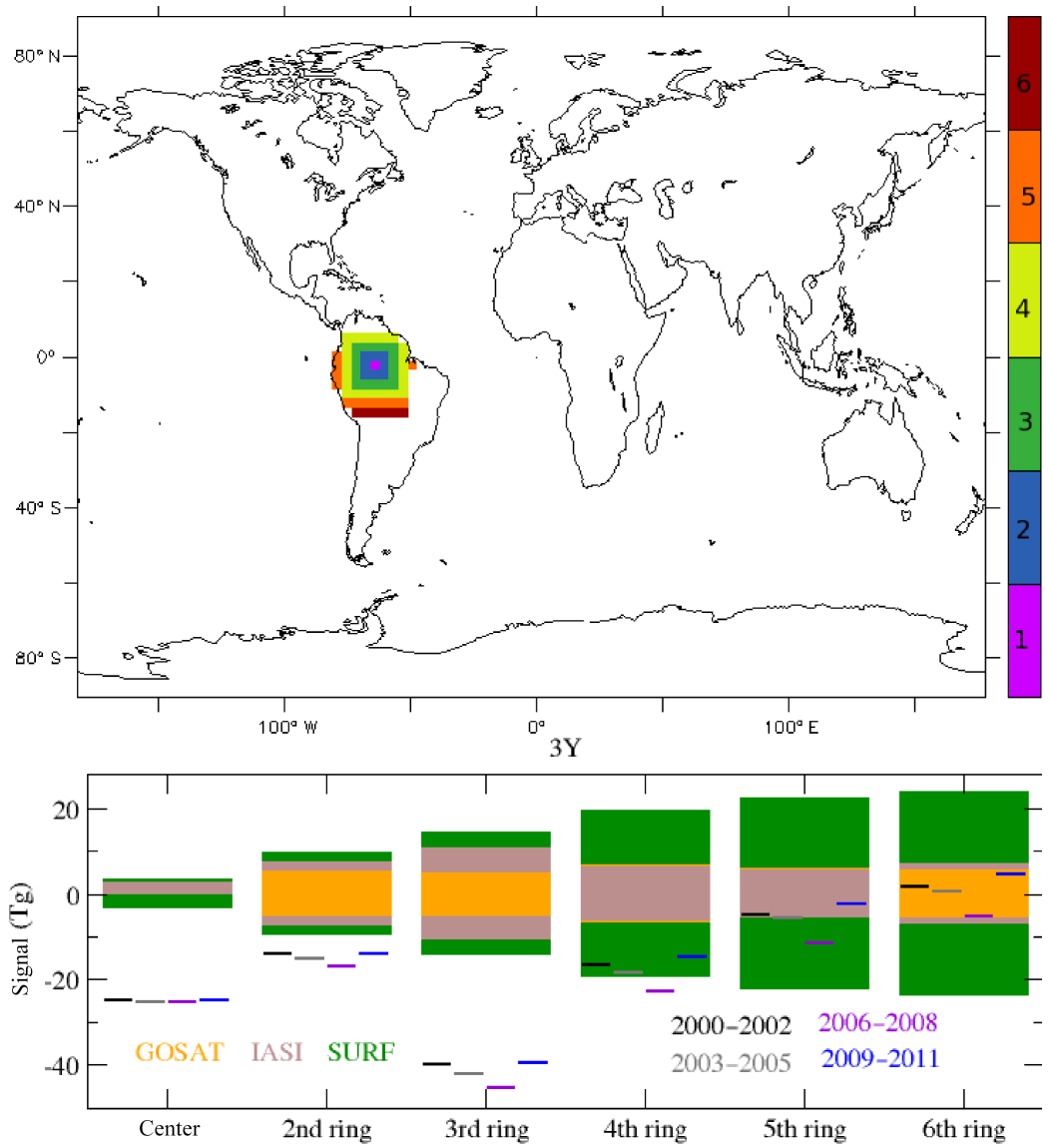

Figure 9. Impact of spatial aggregation in Amazonia on noise (bars) and signal (box plots with median, 25 and $75 \%$ ) over 3-year time windows, from a unique pixel to larger rings around it. Detection is achieved when the signal is larger than the noise, i.e., for all the occurrences which lay outside the matching colored bar.

and NorthAfrEast, in which mainly positive anomalies are detected (IASI and SURF) or both positive and negative anomalies (GOSAT). The regional scale in the Southern Hemisphere confirms the better detection with signal PBSURF (Amazonia, SouthSAm, SouthernAfr). In Amazonia, the (mainly positive) signals are detectable by GOSAT and IASI, but China (respectively India) is not any more (respectively poorly) detectable using PBSURF.

At the yearly scale (Table A3), the detection rates are shifted to the south (from TropN and MidN to TropS). Detection rates higher than $50 \%$ are found in Amazonia for GOSAT and IASI, and in Europe for GOSAT.

One important outcome of this sensitivity test to the signal is that some regional or hemispheric flux anomalies are detected but the localization of the detected signal varies depending on the inversion characteristics (including the observations used). This is of course one important limitation in attributing the observed atmospheric changes to particular regions and to the underlying emission processes.

The impact of the signal on the detection of anomalies has also been tested by using a variational inversion at the pixel scale assimilating both surface and IASI data. With this signal, the detection rates are higher in the tropics (particularly in India and China) and in the Southern Hemisphere at midlatitudes (not shown). This suggests that the joint assimilation of surface and satellite data may lead to a better localization of the anomalies of the surface methane fluxes. Nevertheless, this requires that the consistency between the two types of data (surface and remote sensed) be improved (Locatelli et al., 2015; Monteil et al., 2013).

\section{Conclusions}

This study aimed at investigating the spatial and temporal scales of methane surface flux anomalies that current atmospheric inversions can detect. To do so, we have proposed a signal-to-noise ratio analysis, the signal being the methane fluxes inferred from a reference surface-based inversion from 2000 to 2011 and the noise being computed from three inversion systems using surface or satellite data (GOSAT and IASI). At the global and semi-hemispheric scales, all observing systems detect flux anomalies at various timescales from 
seasonal (3-month average) to long-term trend (3-year average). At all scales, GOSAT generally shows the best results among the different systems, as could be expected from the density of the data and their sensitivity to surface emissions.

At the regional scale, the results are more variable. In 8 regions out of 20 , anomalies are detected by the three networks; in 5 regions, no anomaly is detected by any of the three systems. The year-to-year changes are detected in 9 regions by GOSAT but with poor detection rates (lower than $40 \%$ ). Longer term trends (3-year averages) in African regions are detected with variable rates by the three systems. In some key regions for the methane cycle, anomalies are hardly detected, both in the case of dominant anthropogenic emissions (North America) or natural emissions (Amazonia, SiberianLowlands). A sensitivity test to the spatial scale through aggregation shows that dipole effects in the retrieved flux anomalies prevent anomalies in Amazonia (as defined in this study) to be detected. Flux anomalies in India and China, two areas with large and mixed (natural and anthropogenic) methane emissions, are generally poorly detected. A sensitivity test with a second signal, also obtained from an inversion with surface constraints, shows that, overall, the detection at a yearly scale remains poor to fair ( $>50 \%$ in Amazonia for the test signal). These tests point at the importance of properly determining the spatial aggregation at which the inferred fluxes are used, with the issue that such an aggregation depends on the inversion system used. This suggests that the ability of the inversions to retrieve significant inter-annual variations in the methane fluxes is not evident and should be evaluated against uncertainties, which are not always computed and/or provided with the inversion products.

The use of another signal (which is from a different surface-based inversion) does not change the main conclusion that anomalies at the regional scale are not well detected but shows that the regions which are not seen may be different: some yearly changes in Amazonia can be detected but tropical Africa is much less detected with the second signal. Therefore, the precise identification of flux anomalies in the tropics appears not to be robust with regard to changes in the inversion used for the signal. This is of course an issue when attributing the increase observed in atmospheric methane since 2006 to a particular region, as already noticed by Locatelli et al. (2015).

Our criterion is based on a $68 \%$ confidence interval $(1 \sigma)$. At almost all regional space-time scales (except in NorthAmBor, AfrEquat at the longer timescales and a few cases in India, Indonesia, EastEurRussia and FarEastSib), the three observing systems would fail the test at $2 \sigma(95 \%)$, a more stringent criterion commonly used in other scientific communities. We also have neglected the impact of likely state-dependent systematic errors in current satellite retrievals and transport models that further reduce the inversion performance to an unknown extent.
Overall, our study may appear to be pessimistic about the skill of current inversions at the regional scale. However, at least two elements put this view into perspective.

First, we focused on the first decade of the 21st century, a time period with relatively flat methane signals. Neither a strong El Niño, nor a large volcanic eruption occurred, contrary to the previous decade (1990-1999). As an illustration, the methane atmospheric growth rate fluctuates from 2 to $16 \mathrm{ppb} \mathrm{yr}^{-1}$ in the 1990 s (standard deviation of yearly annual increase of $\pm 4.5 \mathrm{ppb} \mathrm{yr}^{-1}$ ) as compared to -4 to $+7 \mathrm{ppb} \mathrm{yr}^{-1}$ (standard deviation of yearly annual increase of $\pm 3.5 \mathrm{ppb} \mathrm{yr}^{-1}$ ) in the 2000s (Dlugokencky et al., 2011). This reduces methane flux anomalies and their detectability for a given noise. A time period with larger year-to-year changes in the methane cycle could lead to an improved detectability.

Second, as mentioned in Sect. 2, we have been relatively conservative to estimate the noise, possibly leading to its overestimation, therefore also limiting the detectability of methane flux anomalies.

Our work has several implications for methane inversions.

First, inversion results should never be presented without an extensive uncertainty analysis to distinguish between robust and more hypothetical results. This may seem obvious but such an analysis is not always provided, or only partially, in inversion papers, mostly because of its computational cost.

Second, to increase the detection robustness, the information amount from the satellite data and from the surface sites should be dramatically increased, as shown by the regional differences between the two surface-based inversions (e.g., Africa vs. tropical regions and China) and between the satellite-based inversions. Defining smaller regions, as tested here in Amazonia, may also improve the detection of anomalies in small key areas with intense methane emissions. An increase in the robustness of the attribution of flux anomalies to a particular region goes with the improvement of the consistency of error statistics prescribed for fluxes and observations (Berchet et al., 2015).

Third, as the regions robustly inferred depend on the assimilated data sets, but also on the transport model and inversion setup, it seems important to push for regular comparisons and syntheses of the various transport models and inversion systems, which is at present the only way to approach the full range of uncertainty.

With time, the increase of observations in density, precision and accuracy, if sustained by long-term funding of surface networks and development of satellite instruments, together with the necessary improvement of transport models, should allow to reduce uncertainties in methane flux estimates. The joint assimilation of surface and satellite observations could be a solution to further improve the constraint on methane surface fluxes, if the consistency between surface and remote-sensed data can be improved (Locatelli et al., 2015; Monteil et al., 2013; Cressot et al., 2014). Cloud cover and aerosol layers limit the observability of key regions, such as China and India or even Amazonia, and induce systematic 
errors in passive satellite instruments (e.g., Buchwitz et al., 2016). Solar-based satellite instruments also provide limited data at high latitudes. The future space mission MERLIN, based on a differential active lidar measurement with a very small spot on the ground, should overcome these issues and provide data at all latitudes and all seasons (Kiemle et al., 2014). In this context, MERLIN seems to be a promising mission to improve some of the limitations raised in this paper.

\section{Data availability}

The real surface and satellite data that correspond to our simulations are available from, respectively, http://ds.data.jma. go.jp/gmd/wdcgg/ and http://ghgcci.physik.uni-bremen.de/. 


\section{Appendix A: Appendix tables}

Table A1. Yearly mean number of observations over the period used for the Monte Carlo noise computation (October 2009-September 2010) in the various regions for the three observing systems.

\begin{tabular}{|c|c|c|c|c|}
\hline Region & Area $\left(\times 10^{6} \mathrm{~km}^{2}\right)$ & GOSAT & IASI & SURF \\
\hline Global & 510 & 32348 & 240084 & 1722 \\
\hline BorN & 31 & 92 & 00 & 172 \\
\hline MidN & 91 & 9060 & 00 & 556 \\
\hline TropN & 126 & 14934 & 121756 & 602 \\
\hline TropS & 128 & 6118 & 107148 & 156 \\
\hline MidS & 95 & 2132 & 9078 & 140 \\
\hline BorS & 37 & 00 & 00 & 96 \\
\hline NorthAmBor & 14 & 194 & 00 & 00 \\
\hline USA & 11 & 2516 & 2218 & 124 \\
\hline CentralAm & 05 & 608 & 6328 & 24 \\
\hline Amazonia & 07 & 802 & 3366 & 00 \\
\hline SouthSAm & 10 & 1780 & 3068 & 24 \\
\hline NorthAfrWest & 10 & 4986 & 4564 & 94 \\
\hline NorthAfrEast & 07 & 3756 & 5148 & 00 \\
\hline AfrEquat & 07 & 1394 & 3572 & 14 \\
\hline SouthernAfr & 07 & 1488 & 3246 & 28 \\
\hline Europe & 06 & 572 & 00 & 94 \\
\hline EastEurRussia & 07 & 896 & 00 & 00 \\
\hline MiddleEast & 06 & 2456 & 3748 & 26 \\
\hline SiberianLowlands & 02 & 170 & 00 & 00 \\
\hline SiberianHighlands & 05 & 126 & 00 & 00 \\
\hline FarEastSib & 03 & 54 & 00 & 00 \\
\hline CentralAsia & 12 & 3864 & 694 & 74 \\
\hline India & 03 & 1180 & 4190 & 00 \\
\hline China & 05 & 1164 & 4574 & 00 \\
\hline Indonesia & 07 & 312 & 3324 & 26 \\
\hline AustrNZ & 10 & 3308 & 4362 & 50 \\
\hline
\end{tabular}


Table A2. Detection of the signal consisting in the anomalies at the seasonal timescale (JFM, AMJ, JAS, OND). The signal is the difference between each quarter in the 2000-2011 period (i.e., 48 occurrences) and the 2004-2005 average from PBSURF. The noise is computed at the quarter timescale from each of the three observation systems, GOSAT, IASI and SURF. See Sects. 2.4 and 2.3 for details. In each cell of the table, we show $X \%( \pm T T)( \pm Y Y / \pm Z Z)$ where $X \%$ is the percentage of quarterly anomalies detected, $( \pm T T)$ is the difference with REFSURF (Table 1), $\pm Y Y$ is the difference in the number of positive anomalies detected compared to REFSURF and $\pm Z Z$ is the difference

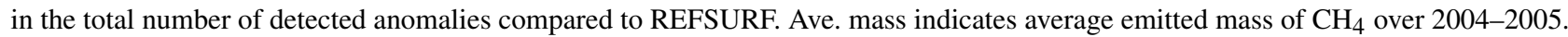

\begin{tabular}{|c|c|c|c|}
\hline $\begin{array}{l}\text { Region } \\
\text { Ave. mass (Tg) } \\
\text { REFSURF/PBSURF }\end{array}$ & GOSAT & IASI & SURF \\
\hline Global 517/499 & $87 \%(-6)(-10 /-3)$ & $72 \%(-19)(-9 /-9)$ & $72 \%(-19)(-9 /-9)$ \\
\hline BorN 18/17 & $75 \%(+30)(+2 /+14)$ & $75 \%(+36)(+5 /+17)$ & $77 \%(+23)(0 /+11)$ \\
\hline MidN 177/172 & $66 \%(-11)(-2 /-5)$ & $35 \%(-4)(0 /-2)$ & $62 \%(-8)(0 /-4)$ \\
\hline TropN 194/165 & $47 \%(-40)(-10 /-19)$ & $27 \%(-33)(-5 /-16)$ & $29 \%(-37)(-6 /-18)$ \\
\hline TropS $115 / 120$ & $29 \%(+21)(+9 /+10)$ & $31 \%(+19)(+9 /+9)$ & $10 \%(+10)(+5 /+5)$ \\
\hline MidS 12/25 & $\varnothing$ & $\varnothing$ & $04 \%(+4)(0 /+2)$ \\
\hline BorS 1/0 & $\varnothing$ & $\varnothing$ & $\varnothing$ \\
\hline NorthAmBor $20 / 8$ & $64 \%(-15)(-2 /-7)$ & $43 \%(-15)(+3 /-7)$ & $58 \%(-17)(0 /-8)$ \\
\hline USA $37 / 54$ & $31 \%(+31)(+8 /+15)$ & $06 \%(+6)(+1 /+3)$ & $10 \%(+10)(+3 /+5)$ \\
\hline CentralAm 17/13 & 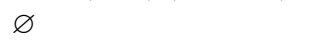 & $02 \%(+2)(+1 /+1)$ & $\varnothing$ \\
\hline Amazonia 38/31 & $45 \%(+31)(+19 /+15)$ & $35 \%(+29)(+15 /+14)$ & $04 \%(+4)(+2 /+2)$ \\
\hline SouthSAm 30/45 & $45 \%(+41)(+15 /+20)$ & $08 \%(+8)(+3 /+4)$ & $20 \%(+20)(+6 /+10)$ \\
\hline NorthAfrWest 13/13 & $41 \%(+31)(+7 /+15)$ & $16 \%(+16)(+8 /+8)$ & $16 \%(+16)(+8 /+8)$ \\
\hline NorthAfrEast 11/12 & $39 \%(+35)(+10 /+17)$ & $25 \%(+25)(+12 /+12)$ & $25 \%(+25)(+12 /+12)$ \\
\hline AfrEquat $32 / 33$ & $18 \%(-4)(-10 /-2)$ & $10 \%(-6)(-8 /-3)$ & $00 \%(-2)(-1 /-1)$ \\
\hline SouthernAfr 10/14 & $43 \%(+43)(+7 /+21)$ & $14 \%(+14)(+5 /+7)$ & $14 \%(+14)(+5 /+7)$ \\
\hline Europe $33 / 33$ & $14 \%(+8)(-3 /+4)$ & $04 \%(+4)(0 /+2)$ & $12 \%(+8)(-2 /+4)$ \\
\hline EastEurRussia 30/27 & $33 \%(0)(-2 / 0)$ & $\varnothing$ & $10 \%(-6)(-3 /-3)$ \\
\hline MiddleEast 16/14 & $\varnothing$ & $\varnothing$ & $\varnothing$ \\
\hline SiberianLowlands 8/14 & $89 \%(+46)(+2 /+22)$ & $60 \%(+58)(+11 /+28)$ & $85 \%(+42)(+2 /+20)$ \\
\hline SiberianHighlands 5/4 & $22 \%(+14)(+7 /+7)$ & $12 \%(+8)(+4 /+4)$ & $20 \%(+16)(+8 /+8)$ \\
\hline FarEastSib 1/2 & $52 \%(+36)(+4 /+17)$ & $50 \%(+42)(+8 /+20)$ & $50 \%(+42)(+8 /+20)$ \\
\hline CentralAsia 28/32 & $20 \%(+14)(+5 /+7)$ & $\varnothing$ & $08 \%(+2)(+1 /+1)$ \\
\hline India 50/45 & $10 \%(-46)(-11 /-22)$ & $02 \%(-33)(-5 /-16)$ & $00 \%(-25)(0 /-12)$ \\
\hline China $64 / 46$ & $00 \%(-14)(-3 /-7)$ & $00 \%(-4)(0 /-2)$ & $00 \%(-10)(-1 /-5)$ \\
\hline Indonesia $36 / 33$ & $06 \%(0)(0 / 0)$ & $12 \%(+6)(+2 /+3)$ & $00 \%(-4)(-2 /-2)$ \\
\hline AustrNZ 6/6 & $\varnothing$ & $\varnothing$ & $\varnothing$ \\
\hline
\end{tabular}


Table A3. Detection of the signal consisting in the anomalies at the yearly timescale. The signal is the difference between each year in the 2000-2011 period (i.e., 12 occurrences) and the 2004-2005 average from PBSURF. The noise is computed at the yearly timescale from each of the three observation systems, GOSAT, IASI and SURF. See Sects. 2.4 and 2.3 for details. In each cell of the table, we show $X \%( \pm T T)$ $( \pm Y Y / \pm Z Z$ ) where $X \%$ is the percentage of yearly anomalies detected, $( \pm T T$ ) is the difference with REFSURF (Table 2 ), $\pm Y Y$ is the difference in the number of positive anomalies detected compared to REFSURF and $\pm Z Z$ is the difference in the total number of detected anomalies compared to REFSURF. Ave. mass indicates average emitted mass of $\mathrm{CH}_{4}$ over 2004-2005.

\begin{tabular}{llll}
\hline $\begin{array}{l}\text { Region } \\
\text { Ave. mass (Tg) } \\
\text { REFSURF/PBSURF }\end{array}$ & GOSAT & IASI & SURF \\
\hline Global 517/499 & $58 \%(-17)(-1 /-2)$ & $66 \%(-9)(0 /-1)$ & $4 \% 1(-17)(-2 /-2)$ \\
BorN 18/17 & $\varnothing$ & $\varnothing$ & $\varnothing$ \\
MidN 177/172 & $00 \%(-8)(-1 /-1)$ & $\varnothing$ & $00 \%(-8)(-1 /-1)$ \\
TropN 194/165 & $00 \%(-50)(-6 /-6)$ & $\varnothing$ & $00 \%(-25)(-3 /-3)$ \\
TropS 115/120 & $41 \%(+25)(+3 /+3)$ & $41 \%(+25)(+3 /+3)$ & $41 \%(+25)(+3 /+3)$ \\
MidS 12/25 & $\varnothing$ & $\varnothing$ & $\varnothing$ \\
BorS 1/0 & $\varnothing$ & $\varnothing$ & $\varnothing$ \\
NorthAmBor 20/8 & $25 \%(+25)(+3 /+3)$ & $\varnothing$ & $\varnothing$ \\
USA 37/54 & $\varnothing$ & $\varnothing$ & $\varnothing$ \\
CentralAm 17/13 & $\varnothing$ & $\varnothing$ & $\varnothing$ \\
Amazonia 38/31 & $58 \%(+50)(+7 /+6)$ & $58 \%(+58)(+7 /+7)$ & $08 \%(+8)(+1 /+1)$ \\
SouthSAm 30/45 & $33 \%(+33)(+3 /+4)$ & $16 \%(+16)(+2 /+2)$ & $16 \%(+16)(+2 /+2)$ \\
NorthAfrWest 13/13 & $00 \%(-33)(-4 /-4)$ & $\varnothing$ & $\varnothing$ \\
NorthAfrEast 11/12 & $00 \%(-8)(-1 /-1)$ & $\varnothing$ & $\varnothing$ \\
AfrEquat 32/33 & $00 \%(-33)(-4 /-4)$ & $00 \%(-33)(-4 /-4)$ & $00 \%(-25)(-3 /-3)$ \\
SouthernAfr 10/14 & $16 \%(+16)(+1 /+2)$ & $\varnothing$ & $\varnothing$ \\
Europe 33/33 & $50 \%(+34)(-2 /+4)$ & $08 \%(+8)(0 /+1)$ & $33 \%(+33)(0 /+4)$ \\
EastEurRussia 30/27 & $16 \%(+16)(+1 /+2)$ & $\varnothing$ & $\varnothing$ \\
MiddleEast 16/14 & $\varnothing$ & $\varnothing$ & $\varnothing$ \\
SiberianLowlands 8/+14 & $16 \%(+16)(+1 /+2)$ & $\varnothing$ & $\varnothing$ \\
SiberianHighlands 5/4 & $00 \%(-8)(-1 /-1)$ & $\varnothing$ & $\varnothing$ \\
FarEastSib 1/2 & $00 \%(-8)(-1 /-1)$ & $\varnothing$ & $\varnothing$ \\
CentralAsia 28/32 & $00 \%(-8)(0 /-1)$ & $\varnothing$ & $\varnothing$ \\
India 50/45 & $\varnothing$ & $\varnothing$ & $\varnothing$ \\
China 64/46 & $\varnothing$ & $\varnothing$ & $\varnothing$ \\
Indonesia 36/33 & $33 \%(+17)(+2 /+2)$ & $33 \%(+17)(+2 /+2)$ & $\varnothing$ \\
AustrNZ 6/6 & $\varnothing$ & $\varnothing$ & $\varnothing$ \\
\hline
\end{tabular}


Acknowledgements. The authors are very grateful to the many people involved in the surface and satellite measurement and in the archiving of these data. The authors particularly thank E. J. Dlugokencky (NOAA), S. A. Montzka (NOAA), C. Crevoisier (LMD), H. Boesch (University of Leicester), R. Parker (University of Leicester), P. B. Krummel (CSIRO), L. P. Steele (CSIRO), R. L. Langenfelds (CSIRO), S. Nichol (NIWA) and D. Worthy (EC). We acknowledge the contributors to the World Data Center for Greenhouse Gases for providing their data of methane and methyl-chloroform atmospheric mole fractions. The first author is funded by CNES and CEA. P. J. Rayner is in receipt of an Australian Professorial Fellowship (DP1096309). This work was performed using HPC resources from CCRT under the allocation 2014-t2014012201 made by GENCI (Grand Equipement National de Calcul Intensif) and a DSM allocation. We also thank the computing support team of the LSCE led by F. Marabelle.

Edited by: B. N. Duncan

Reviewed by: R. Kawa and one anonymous referee

\section{References}

Berchet, A., Pison, I., Chevallier, F., Bousquet, P., Bonne, J.-L., and Paris, J.-D.: Objectified quantification of uncertainties in Bayesian atmospheric inversions, Geosci. Model Dev., 8, 15251546, doi:10.5194/gmd-8-1525-2015, 2015.

Bergamaschi, P., Frankenberg, C., Meirink, J., Krol, M., Dentener, F., Wagner, T., Platt, U., Kaplan, J., Körner, S., Heimann, M., Dlugokencky, E. J., and Goede, A.: Satellite chartography of atmospheric methane from SCIAMACHY on board ENVISAT: 2. Evaluation based on inverse model simulations, J. Geophys. Res.-Atmos., 112, D02304, doi:10.1029/2006JD007268, 2007.

Bergamaschi, P., Houweling, S., Segers, A., Krol, M., Frankenberg, C., Scheepmaker, R., Dlugokencky, E., Wofsy, S., Kort, E., Sweeney, C., Schuck, T., Brenninkmeijer, C., Chen, H., Beck, V., and Gerbig, C.: Atmospheric $\mathrm{CH}_{4}$ in the first decade of the $21 \mathrm{st}$ century: Inverse modeling analysis using SCIAMACHY satellite retrievals and NOAA surface measurements, J. Geophys. Res.Atmos., 118, 7350-7369, 2013.

Bousquet, P., Ciais, P., Miller, J. B., Dlugokencky, E. J., Hauglustaine, D. A., Prigent, C., Van der Werf, G. R., Peylin, P., Brunke, E. G., Carouge, C., Langenfelds, R. L., Lathiere, J., Papa, F., Ramonet, M., Schmidt, M., Steele, L. P., Tyler, S. C., and White, J.: Contribution of anthropogenic and natural sources to atmospheric methane variability, Nature, 443, 439443, doi:10.1038/nature05132, 2006.

Bousquet, P., Ringeval, B., Pison, I., Dlugokencky, E. J., Brunke, E.G., Carouge, C., Chevallier, F., Fortems-Cheiney, A., Frankenberg, C., Hauglustaine, D. A., Krummel, P. B., Langenfelds, R. L., Ramonet, M., Schmidt, M., Steele, L. P., Szopa, S., Yver, C., Viovy, N., and Ciais, P.: Source attribution of the changes in atmospheric methane for 2006-2008, Atmos. Chem. Phys., 11, 3689-3700, doi:10.5194/acp-11-3689-2011, 2011.

Buchwitz, M., Dils, B., Boesch, H., Crevoisier, C., and Detmers, R., Frankenberg, C., Hasekamp, O., Hewson, W., Laeng, A., Noel, S., Nothold, J., Parker, R., Reuter, M., and Schneising, O.: Product Validation and Intercomparison Report (PVIR) for the Essential Climate Variable (ECV) Greenhouse Gases
(GHG), Tech. Rep. report version 4, ESA Climate Change Initiative (CCI), available at: http://www.esa-ghg-cci.org/?q=webfm_ send/300, last access: 10 February 2016.

Chevallier, F., Fisher, M., Peylin, P., Serrar, S., Bousquet, P., Breon, F., Chédin, A., and Ciais, P. F.: Inferring $\mathrm{CO}_{2}$ sources and sinks from satellite observations: Method and application to TOVS data, J. Geophys. Res., 110, D24309, doi:10.1029/2005JD006390, 2005.

Chevallier, F., Bréon, F.-M., and Rayner, P.: The contribution of the Orbiting Carbon Observatory to the estimation of $\mathrm{CO}_{2}$ sources and sinks: Theoretical study in a variational data assimilation framework, J. Geophys. Res., 112, D09307, doi:10.1029/2006JD007375, 2007.

Connor, B. J., Boesch, H., Toon, G., Sen, B., Miller, C., and Crisp, D.: Orbiting Carbon Observatory: Inverse method and prospective error analysis, J. Geophys. Res.-Atmos., 113, D05305, doi:10.1029/2006JD008336, 2008.

Cressot, C., Chevallier, F., Bousquet, P., Crevoisier, C., Dlugokencky, E. J., Fortems-Cheiney, A., Frankenberg, C., Parker, R., Pison, I., Scheepmaker, R. A., Montzka, S. A., Krummel, P. B., Steele, L. P., and Langenfelds, R. L.: On the consistency between global and regional methane emissions inferred from SCIAMACHY, TANSO-FTS, IASI and surface measurements, Atmos. Chem. Phys., 14, 577-592, doi:10.5194/acp-14-577-2014, 2014.

Crevoisier, C., Nobileau, D., Fiore, A. M., Armante, R., Chédin, A., and Scott, N. A.: Tropospheric methane in the tropics - first year from IASI hyperspectral infrared observations, Atmos. Chem. Phys., 9, 6337-6350, doi:10.5194/acp-9-6337-2009, 2009.

Desroziers, G., Berre, L., Chapnik, B., and Poli, P.: Diagnosis of observation, background and analysis-error statistics in observation space, Q. J. Roy. Meteor. Soc., 131, 3385-3396, 2005.

Dlugokencky, E., Steele, L., Lang, P., and Masarie, K.: The growth rate and distribution of atmospheric methane, J. Geophys. Res., 99, 17021-17043, doi:10.1029/94JD01245, 1994.

Dlugokencky, E., Bruhwiler, L., White, J., Emmons, L., Novelli, P., Montzka, S., Masarie, K., Crotwell, A., Miller, J., and Gatti, L.: Observational constraints on recent increases in the atmospheric $\mathrm{CH}_{4}$ burden, Geophys. Res. Lett., 36, L18803, doi:10.1029/2009GL039780, 2009.

Dlugokencky, E. J., Nisbet, E. G., Fisher, R., and Lowry, D.: Global atmospheric methane: budget, changes and dangers, Philos. T. R. Soc. Lond. A, 369, 2058-2072, doi:10.1098/rsta.2010.0341, 2011.

Francey, R., Steele, L., Langenfelds, R., and Pak, B.: High Precision Long-Term Monitoring of Radiatively Active and Related Trace Gases at Surface Sites and from Aircraft in the Southern Hemisphere Atmosphere, J. Atmos. Sci., 56, 279-285, 1999.

Gilbert, J.-C. and Lemaréchal, C.: Some numerical experiments with variable-storage quasi-Newton algorithms, Math. Programm., 45, 407-435, 1989.

Hausmann, P., Sussmann, R., and Smale, D.: Contribution of oil and natural gas production to renewed increase in atmospheric methane (2007-2014): top-down estimate from ethane and methane column observations, Atmos. Chem. Phys., 16, 3227-3244, doi:10.5194/acp-16-3227-2016, 2016.

Hourdin, F., Musat, I., Bony, S., Braconnot, P., Codron, F., Dufresne, J., Fairhead, L., Filiberti, M., Friedlingstein, P., Grandpeix, J., Krinner, G., LeVan, P., Li, Z.-X., and Lott, F.: The LMDZ4 general circulation model: climate performance and 
sensitivity to parametrized physics with emphasis on tropical convection, Clim. Dynam., 27, 787-813, 2006.

Houweling, S., Kaminski, T., Dentener, F., Lelieveld, J., and Heimann, M.: Inverse modeling of methane sources and sinks using the adjoint of a global transport model, J. Geophys. Res., 104, 26-137, 1999.

Kaminski, T., Rayner, P. J., Heimann, M., and Enting, I. G.: On aggregation errors in atmospheric transport inversions, J. Geophys. Res., 105, 4703-4715, 2001.

Kiemle, C., Kawa, S. R., Quatrevalet, M., and Browell, E. V.: Performance simulations for a spaceborne methane lidar mission, J. Geophys. Res.-Atmos., 119, 4365-4379, 2014.

Kirschke, S., Bousquet, P., Ciais, P., et al.: Three decades of global methane sources and sinks, Nat. Geosci., 6, 813-823, 2013.

Locatelli, R., Bousquet, P., Hourdin, F., Saunois, M., Cozic, A., Couvreux, F., Grandpeix, J.-Y., Lefebvre, M.-P., Rio, C., Bergamaschi, P., Chambers, S. D., Karstens, U., Kazan, V., van der Laan, S., Meijer, H. A. J., Moncrieff, J., Ramonet, M., Scheeren, H. A., Schlosser, C., Schmidt, M., Vermeulen, A., and Williams, A. G.: Atmospheric transport and chemistry of trace gases in LMDz5B: evaluation and implications for inverse modelling, Geosci. Model Dev., 8, 129-150, doi:10.5194/gmd-8-129-2015, 2015.

Lowe, D., Brenninkmeijer, C., Tyler, S., and Dlugkencky, E.: Determination of the Isotopic Composition of Atmospheric Methane and its Application in the Antarctic, J. Geophys. Res., 96, 1545515467, 1991.

Matthews, E., Fung, I., and Lerner, J.: Methane emission from rice cultivation: Geographic and seasonal distribution of cultivated areas and emissions, Global Biogeochem. Cy., 5, 3-24, 1991.

Monteil, G., Houweling, S., Butz, A., Guerlet, S., Schepers, D., Hasekamp, O., Frankenberg, C., Scheepmaker, R., Aben, I., and Röckmann, T.: Comparison of $\mathrm{CH}_{4}$ inversions based on 15 months of GOSAT and SCIAMACHY observations, J. Geophys. Res.-Atmos., 118, 11807-11823, doi:10.1002/2013JD019760, 2013.

Montzka, S., Krol, M., Dlugokencky, E., Hall, B., Jöckel, P., and Lelieveld, J.: Small interannual variability of global atmospheric hydroxyl, Science, 331, 67-69, doi:10.1126/science.1197640, 2011.
National Weather Service - Climate Prediction Center: Cold \& Warm Episodes by Season, available at: http://www.cpc.ncep.noaa.gov/products/analysis_monitoring/ ensostuff/ensoyears.shtml, last access: 8 February 2016.

Nisbet, E. G., Dlugokencky, E. J., Bousquet, P.: Methane on the rise-again, Science, 343, 493-495, 2014.

Parker, R., Boesch, H., Cogan, A., Fraser, A., Feng, L., Palmer, P. I., Messerschmidt, J., Deutscher, N., Griffith, D. W., Notholt, J., Wennberg, P. O., and Wunch, D.: Methane observations from the Greenhouse Gases Observing SATellite: Comparison to groundbased TCCON data and model calculations, Geophys. Res. Lett., 38, L15807, doi:10.1029/2011GL047871, 2011.

Pison, I., Bousquet, P., Chevallier, F., Szopa, S., and Hauglustaine, D.: Multi-species inversion of $\mathrm{CH}_{4}, \mathrm{CO}$ and $\mathrm{H}_{2}$ emissions from surface measurements, Atmos. Chem. Phys., 9, 5281-5297, doi:10.5194/acp-9-5281-2009, 2009.

Pison, I., Ringeval, B., Bousquet, P., Prigent, C., and Papa, F.: Stable atmospheric methane in the 2000s: key-role of emissions from natural wetlands, Atmos. Chem. Phys., 13, 11609-11623, doi:10.5194/acp-13-11609-2013, 2013.

Rigby, M., Prinn, R., Fraser, P., Simmonds, P., Langenfelds, R., Huang, J., Cunnold, D., Steele, L., Krummel, P., Weiss, R., O’Doherty, S., Salameh, P., Wang, H., Harth, C., Mülhe, J., and Porter, L.: Renewed growth of atmospheric methane, Geophys. Res. Lett., 35, L22805, doi:10.1029/2008GL036037, 2008.

Schaefer, H., Fletcher, S. E. M., Veidt, C., Lassey, K. R., Brailsford, G. W., Bromley, T. M., Dlugokencky, E. J., Michel, S. E., Miller, J. B., Levin, I., Lowe, D. C., Martin, R. J., Vaughn, B. H., and White, J. W. C.: A 21st-century shift from fossil-fuel to biogenic methane emissions indicated by ${ }^{13} \mathrm{CH}^{4}$, Science, 352, 8084, doi:10.1126/science.aad2705, 2016.

Worthy, D. E., Chan, E., Ishizawa, M., Chan, D., Poss, C., Dlugokencky, E. J., Maksyutov, S., and Levin, I.: Decreasing anthropogenic methane emissions in Europe and Siberia inferred from continuous carbon dioxide and methane observations at Alert, Canada, J. Geophys. Res.-Atmos., 114, D10301, doi:10.1029/2008JD011239, 2009. 